\title{
Seasonal Variability of the Transport through the Yucatan Channel from Observations
}

\author{
GABRIELA ATHIÉ \\ CONACYT-Instituto de Ciencias Marinas y Pesquerías, Universidad Veracruzana, Boca del Rio, Veracruz, Mexico \\ Julio Sheinbaum, Julio Candela, José OchoA, And Paula Pérez-Brunius \\ Centro de Investigación Científica y de Educación Superior de Ensenada, Ensenada, Baja California, Mexico
}

ANGELICA ROMERO-ARTEAGA

Universidad Autónoma de Baja California, Ensenada, Baja California, Mexico

(Manuscript received 19 December 2018, in final form 6 November 2019)

\begin{abstract}
The seasonal cycle of transport through the Yucatan Channel is estimated from 59 months of direct mooring measurements and 23 years of a transport proxy from AVISO sea level across the channel. Both exhibit a seasonal cycle with a maximum in summer (July-August) but have a minimum in March for the mooring and in November for AVISO data. The annual and semiannual harmonics explain respectively $19 \%(\sim 32 \%)$ and $6 \%(\sim 4 \%)$ of the subinertial variance of the moored (proxy) transports. Seasonal variations of zonal wind stress and anticyclonic wind stress curl over the Cayman Sea appear to be positively correlated with transport in Yucatan Channel and the northward extension of the Loop Current during the summer, agreeing to some extent with modeling results previously reported. Transport increments during summer coincide with enhanced regional easterly winds and anticyclonic wind stress curl in $60 \%$ of the cases (of 23 years). However, this connection is not as tight as model results suggest during winter. The summer correlation only appears to be valid in a broad statistical sense since it is modulated by large interannual and higher-frequency variability. Moored time series confirm previous results that the transport signal on the western side of the channel is quite different from the total Yucatan Channel transport and that eddy kinetic energy at higher frequencies (50-100 days) dominates the variability and is characterized by a relatively low net transport signal, with flow of opposite signs on each side of the channel.
\end{abstract}

\section{Introduction}

Since earlier studies in the region (Maul 1977; Molinari et al. 1978; Sturges 1994), a key question was whether or not there was seasonality in the Loop Current (LC) behavior and whether it had an impact on its eddy shedding process. Over the years, the issue has been addressed with numerical models relating the seasonal variations with those of the wind (e.g., Sturges and Evans 1983; Rousset and Beal 2010, 2011; Chang and Oey 2012, 2013). The first studies based on observations (e.g., Molinari et al. 1978) used 3 years of hydrographic data and concluded there was seasonality of the flow through the Yucatan Channel (within the top 500-m depth), with a maximum in June in phase with the maximum intrusion of the LC. Subsequently, studies of

Corresponding author: G. Athié, gathie@uv.mx continuous velocity time series from mooring data did not find a clear seasonal signal in Yucatan transport (Abascal et al. 2003; Candela et al. 2003), though these series had a duration of less than 2 years, which does not allow for the determination of a reliable seasonal cycle. More recently, Rousset and Beal (2010) used 90 (oblique) crossings of shipboard ADCP data through the Yucatan Channel over 5 years, with an average of 7.5 near-surface measurements per month and two samples per month down to $\sim 1200-\mathrm{m}$ depth. They complemented these observations with numerical model outputs below that depth to calculate monthly means of the Yucatan Channel transport. Their results for the period 2001-06 indicated a semiannual behavior with an increase of $2.5 \mathrm{~Sv}\left(1 \mathrm{~Sv} \equiv 10^{6} \mathrm{~m}^{3} \mathrm{~s}^{-1}\right)$ in July and $2.7 \mathrm{~Sv}$ in February. Other numerical model results (Chang and Oey 2012, 2013, from here on referred to as CO) suggested there was an asymmetric semiannual cycle of the Yucatan 
Channel transport and the Loop Current eddy releases, with one maximum in summer (June-July), a second weaker maximum in winter (January-February), and a minimum in fall. The seasonal range of their modeled Yucatan Channel transport anomalies is $\sim 1.5 \mathrm{~Sv}$ in summer ( $0.5 \mathrm{~Sv}$ in February) and $\sim-1 \mathrm{~Sv}$ in fall, which is about half of what is observed (see section 2 below). From these numerical studies, $\mathrm{CO}$ suggests that wind forcing over the northwestern Caribbean and Gulf of Mexico (GoM) regulates the seasonality of the transport through the Yucatan Channel, the LC extension, and the anticyclonic eddy detachments. Their argument is as follows: during summer and winter, easterly winds over the Caribbean intensify and increase the Yucatan transport (lagged by 1 month), which leads to deeper penetration of the LC into the GoM and a tendency of anticyclonic eddy releases about one month after the transport increased. At the same time, during those seasons the easterly winds over the GoM weaken, and these conditions increase the likelihood of eddy detachments (see CO for details); the opposite situation occurs during spring and fall.

It is worth mentioning that other modeling studies contest some of CO's ideas. For example, the numerical results of Lin et al. (2009) indicate that the highest transports in the channel occur when the LC is less extended and outflows almost directly toward the Florida Straits. Mildner et al. (2013) conclude it is not wind stress forcing but internal variability of the anticyclonic bulge position of the LC what controls the variability in transport across the Yucatan Channel. Perhaps connected to this mechanism are the Cuban anticyclones described by Kourafalou et al. (2017), particularly those identified as Type A within the bulge of the LC either involved in blocking the flow or strengthening the Cuban Countercurrent. Rousset and Beal (2011) consider the anticyclonic circulation in the Cayman Sea as the main driver of the circulation in the Yucatan Channel and find no correlation with the wind forcing during their observation period. However, the dynamics of the Cayman Sea circulation and the LC bulge position are not fully discussed in these references.

Mesoscale variability in the Cayman Sea or further upstream could modulate the seasonal transport at the Yucatan perhaps conflicting with the $\mathrm{CO}$ ideas. The modeling study of Jouanno et al. $(2008,2009)$ and the analysis of maps of absolute dynamic topography (MADT) variability of Alvera-Azcárate et al. (2009) suggest eddy variability in the Cayman Sea is high but weaker than in the eastern Caribbean. Both show that baroclinic instability dominates the variability in the eastern Caribbean, whereas Jouanno et al. $(2008,2009)$ indicate barotropic instability is dominant in the Cayman
Sea where the flow is more vertically extended and depicts stronger variability at lower frequencies ( $\sim 100$ days) than the eastern Caribbean ( $\sim 50$ days).

Jouanno and Sheinbaum (2012) also find strong semiannual mesoscale variability in the eastern Caribbean produced by changes in the wind that modify the mean currents and enhance or weaken instabilities. This variability is modulated by interannual variations of similar magnitude. Alvera-Azcárate et al. (2009) also suggest low frequency changes in the strength of the Caribbean Current ( $\sim 4.5$ years) produced by the northsouth MADT slope in the basin related to changes in the winds. They also found significant annual variations, but conclude that they are associated with relatively homogeneous steric changes (surface heating and cooling) and therefore not clearly related to transport variations. Many of the processes referred to above and their possible connection with the Yucatan Channel flow require further investigation and have not been fully addressed in subsequent studies.

The existence of a seasonal cycle of LC extension and eddy releases was thoroughly investigated using several kinds of satellite data between 1978 and 2012 by Hall and Leben (2016). They show that seasonality of LC eddy (LCE) detachments is statistically significant, with two seasons of higher probability for anticyclonic eddies to be released: in August-September (at 95\% confidence level) and in February-March (at 90\% confidence level). They point out that a bimodal distribution of LCE detachments does not imply a biannual cycle since years with two separation events are relatively few. Hall and Leben (2016) also provide a detailed review of the research on the seasonal variability of the LC from both direct measurements and satellite imagery using data from the 1970s to the present.

In many of the previous studies it is common to consider the transport through the Yucatan Channel to be the same as the transport of the Yucatan Current, the latter defined as the intense jet above $\sim 800$-m depth (Sheinbaum et al. 2002) confined to the western side of the Yucatan Channel (west of $85.6^{\circ} \mathrm{W}$; A thié et al. 2015). No distinction between these two different transports is made when discussing their relationship with, for example, the LC extension (Molinari et al. 1978; Lin et al. 2009; Rousset and Beal 2010, 2011; CO). Here, we want to highlight the difference between these transports; hence, we refer to them separately throughout the manuscript (i.e., Yucatan Current transport and transport through the whole Yucatan Channel).

Long time series are needed for a meaningful resolution of the seasonal cycle of the flow through the Yucatan Channel (Abascal et al. 2003; Athié et al. 2015; Hall and Leben 2016) given the characteristics of the 
variability whose spectral content is characterized by an energetic higher-frequency signal (100-day period and shorter; Abascal et al. 2003; Alvera-Azcárate et al. 2009), similar to the one found in the Florida cable time series (Meinen et al. 2010). In the present study, the seasonal cycle of transport through the Yucatan Channel is investigated from $\sim 5$ years of direct (quasicontinuous) mooring measurements across this channel and a transport proxy derived from 23 years of MADT satellite data. The results are compared with the seasonal cycles of local wind in the Caribbean, vorticity through Yucatan Channel, and their connection with the LC extension. The longer time series of altimetry data allows a more robust estimate of the seasonal signal in the transport proxy than the direct mooring measurements, and provides an update of some of the issues discussed in Athié et al. (2015).

The paper is organized as follows. In the next section we describe the data and calculations performed in this study. The third section deals with the seasonal cycle of the transport through the Yucatan Channel from mooring data, the transport proxy calculated from AVISO MADT data, and the transports on the western and eastern sides of the channel addressed separately. In section 4 we analyze the seasonal cycle of wind stress forcing over the Caribbean Sea to evaluate its possible connection with the transport at the Yucatan Channel. In section 5 we look at the Yucatan Current (westernchannel flow from the Caribbean into the GoM), to evaluate the variability and seasonal behavior of its vorticity and its relation to the LC extension. Section 6 provides the conclusions of the work.

\section{Data and methods}

\section{a. Data description}

Since 1999 a strong effort to measure and understand the variability of the current system at the Yucatan Channel has been carried out by the Canek research group from Centro de Investigación Científica y de Educación Superior de Ensenada (CICESE), Mexico. Throughout several of these years, heavily instrumented arrays of moorings that include acoustic Doppler current profilers (ADCPs) and point-measuring current meters have been deployed covering the whole Yucatan Channel (i.e., the region between the Yucatan and Cuba, $86.7^{\circ}-85.0^{\circ} \mathrm{W}$ and $10-2030-\mathrm{m}$ depths at $\sim 21.5^{\circ} \mathrm{N}$ ), with reasonable spatial resolution providing continuous time series of at least one year length [more detail about the mooring arrays can be found in Ochoa et al. (2003), Athié et al. (2015), and Candela et al. (2019)]. Presently, there are 78 months of hourly velocity time series covering the whole channel (Fig. 1). These time series are noncontinuous in time: the first measurement period was from September 1999 to May 2001, then a second period from May 2010 to April 2011, and finally there are 46 months of continuous data from October 2012 to August 2016 (Candela et al. 2019). There are small data gaps in the time series lasting less than a month due to instrument replacement. The time series used here were low-pass filtered using a Lanczos filter with a cutoff period of $48 \mathrm{~h}$ and subsampled daily to filter out tides and other high-frequency motions. The transport estimated from these mooring data between the surface and the bottom will be named Tyuc.

Daily MADT data from the AVISO Ssalto/Duacs multimission altimeter (delayed time products) with $0.25^{\circ}$ spatial resolution are used to estimate a transport proxy in the Yucatan Channel [named Tyuc-proxy and described in detail in Athié et al. (2015)]. The method uses a linear regression between the Cuba-Yucatan sea level difference from AVISO and Tyuc using 120-day running mean series. Here, the Tyuc-proxy was recalculated considering the available 78 months of data at present, with a regression coefficient of $[0.64<$ $0.76<0.85](95 \%$ confidence level). This Tyuc-proxy provides a long-term very reasonable estimate of Tyuc at periods longer than one month, although its standard deviation is $\sim 30 \%$ lower than Tyuc, partly by construction but also because AVISO data underestimate mooring velocities (Athié et al. 2015).

Wind data from the ERA-Interim reanalysis were obtained from the European Centre for Medium-Range Weather Forecasts (ECMWF) with 6-h temporal resolution and $0.25^{\circ}$ spatial resolution with wind velocities taken at 10-m height [see Berrisford et al. (2011) for further information]. Zonal wind stress component $\tau_{x}\left(\mathrm{~N} \mathrm{~m}^{-2}\right)$ and the vertical component of wind stress curl $\nabla \times \tau\left(\mathrm{N} \mathrm{m}^{-3}\right)$ were calculated with the following formulas:

$$
\begin{gathered}
\boldsymbol{\tau}=\rho C_{d} \mathbf{u}\left(u^{2}+v^{2}\right)^{1 / 2}, \\
\nabla \times \boldsymbol{\tau}=\frac{1}{R \cos \theta}\left[\frac{\partial \boldsymbol{\tau}_{y}}{\partial \lambda}-\frac{\partial}{\partial \theta}\left(\boldsymbol{\tau}_{x} \cos \theta\right)\right],
\end{gathered}
$$

where $C_{d}$ in Eq. (1), is the empirical drag coefficient, referred to the 10-m level (Smith 1980), defined by

$$
C_{d}=\frac{1}{10^{3}}\left[0.61+0.063\left(u^{2}+v^{2}\right)\right]^{1 / 2},
$$

$u\left(\boldsymbol{\tau}_{x}\right)$ and $v\left(\boldsymbol{\tau}_{y}\right)$ in Eqs. (1) and (3) are zonal and meridional wind velocity components (the corresponding wind stress components); $10^{-3}$ applies for wind magnitudes between 6 and $22 \mathrm{~m} \mathrm{~s}^{-1}$ and for 

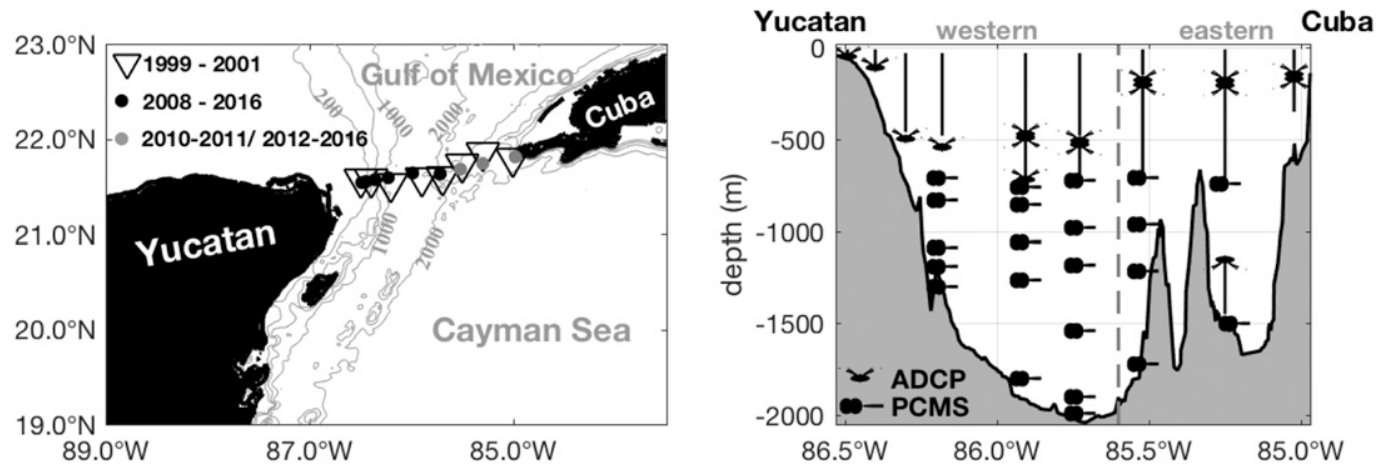

FIG. 1. (left) Location of the moorings during the three measuring periods: September 1999-May 2001, May 2010-April 2011, and October 2012-August 2016 for the Yucatan Channel and March 2008-August 2016 for the western Yucatan Channel. (right) Mooring array configuration with vertical distribution of acoustic Doppler current profilers (ADCP) and point-measuring current meters (PCMS); the western and eastern sides of Yucatan Channel are indicated.

lower wind magnitudes it is $1.1 \times 10^{-3}$; $\rho$ is the density of air [1.2 $\mathrm{kg} \mathrm{m}^{-3}$, Eq. (1)], $\theta$ is the latitude [Eq. (2)], and $R$ in Eq. (2) is Earth's radius [see Nelson (1977) for further information]. The wind stress components and $\nabla \times \tau$ were averaged daily and monthly for the analyses (see below).

\section{b. Methods}

Annual and semiannual harmonics were fitted to the daily Tyuc anomalies for 59 months of measurements, which are the periods $2010-11$ and 2012-16 (the anomalies of Tyuc are estimated with respect the 59-month mean). The Tyuc corresponding to the 1999-2001 measurements was excluded from the calculation because it was a period with anomalous low transport (Athié et al. 2015). The annual and semiannual fitting analysis for Tyuc-proxy series was also carried out for the same periods of mooring data (59 months) as well as for the full 23 years of available data from AVISO. In this paper, the seasonal cycle will be understood as the sum of the annual and semiannual harmonics, while the monthly means for each year will be used to compute a monthly climatology, since the latter may be composed of various harmonics. The seasonal cycles and the spectral analyses were estimated from daily time series, while the rest of the analyses presented in sections 3 and 4 (time series evolution, cross-correlation calculations, and correlation maps) were calculated from monthly averaged series.

To compare transport and energy fluctuations in the channel, a transport efficiency index $I$ was calculated, following Johns and Schott (1987), giving continuity to the Abascal et al. (2003) results for the Yucatan Channel observations between August 1999 and June 2000. The index, defined as $I=\left\langle v^{\prime}\right\rangle^{2} /\left\langle v^{\prime 2}\right\rangle$, compares the areaaveraged velocity fluctuations squared $\left\langle v^{\prime}\right\rangle^{2}$, with the area-averaged EKE of the velocity component perpendicular to the channel $\left\langle v^{\prime 2}\right\rangle$, where $v^{\prime}$ represents the velocity anomaly (temporal mean subtracted) and \langle\rangle$=(1 / A) \int d A$ (where the area $A$ considers the whole channel).

Relative vorticity $\zeta=\partial v / \partial x-\partial u / \partial y$ as well as horizontal shear $\partial v / \partial x$ were estimated at the western edge of the Yucatan Current (taken between $86.375^{\circ}$ and $86.125^{\circ} \mathrm{W}$ ), using daily AVISO geostrophic velocities. The correlation coefficient between the relative vorticity and horizontal shear is 0.83 . Then, it indicates that $\partial v / \partial x$ is a reasonable indicator of the vorticity $\left(r^{2}=0.7\right)$. This result is useful since the term $\partial v / \partial y$ cannot be calculated with the mooring data. Hence, $\partial v / \partial x$ was calculated from daily mooring data near the location mentioned above and then monthly averaged.

Finally, the LC northward extension without the steric signal was calculated by following the $50-\mathrm{cm}$ contour of MADT from AVISO data. It was verified that the $50-\mathrm{cm}$ contour nearly represents the path of highest speed in the LC for this database, instead of the $17-\mathrm{cm}$ contour used with the historical data processed by Leben (2005); the difference probably comes from the different means used in each dataset. Other LC metrics (Leben 2005) were evaluated, such as LC area and volume, with similar results to those presented here. The monthly climatology of the LC northern extension was calculated averaging the northernmost latitude from the LC metrics for each month of the year; detachments and reattachments of the LCEs are not investigated here, since these specific processes are not essential to our analysis [see Schmitz (2005) and Le Hénaff et al. (2012) for further information about LCE dynamics]. The steric signal is the change in MADT associated with the horizontally homogeneous heating or cooling; it was removed by subtracting the daily areal-averaged MADT values in all 

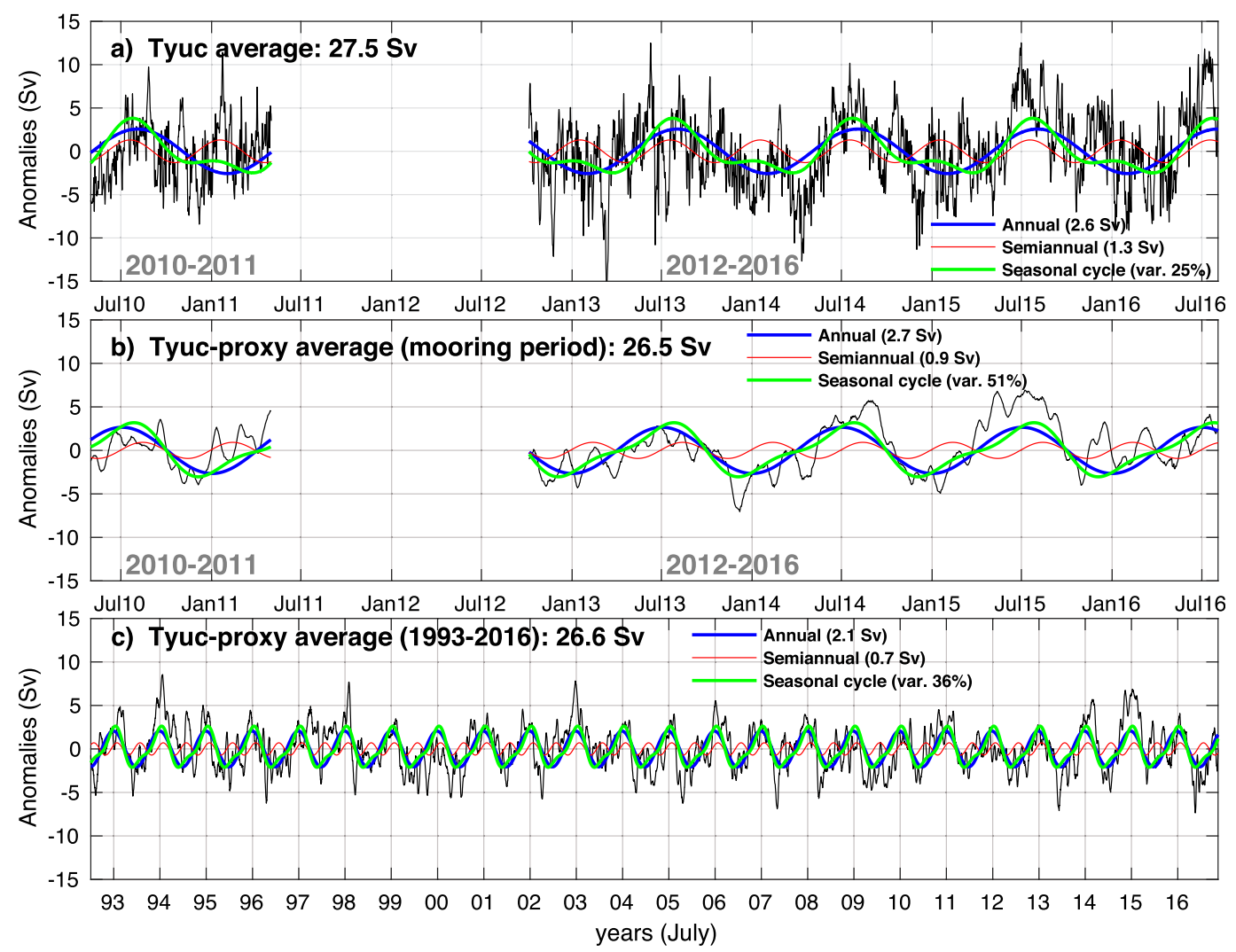

FIG. 2. Yucatan Channel daily transport (black; Sv) and its annual (blue) and semiannual (red) harmonics, as well as the sum of both (green); shown are (a) the mooring's series (2010-11 and 2012-16; total of 59 months), (b) same periods as in (a), but for the Tyuc-proxy of AVISO, and (c) Tyuc-proxy of AVISO between 1993 and 2016 (tick marks correspond to the month of July of each year). The amplitudes of the harmonics and their percentage of variance are indicated for each case (see also Table 1 ).

regions deeper than $200 \mathrm{~m}$ in the GoM using the MADT data (e.g., Liu and Weisberg 2012; Hall and Leben 2016).

\section{Seasonal characteristics of the Yucatan Channel transport}

The annual and semiannual harmonics fitted to the Tyuc anomaly explain $25 \%$ of the subinertial variance in the daily series; the considered period was between May 2010-April 2011 and October 2012-August 2016 (Fig. 2a; see also Table 1). The annual harmonic captures more of the seasonal signal with an amplitude of $2.6 \mathrm{~Sv}$, while the semiannual component has an amplitude of $1.3 \mathrm{~Sv}$ and its variance only accounts for $\sim 6 \%$ of the subinertial variance (Table 1). For comparison, the analysis of Tyuc-proxy from daily AVISO series for the same dates (Fig. 2b) results in an annual component of $2.7 \mathrm{~Sv}$, (similar to mooring results) but the amplitude of the semiannual component is $\sim 30 \%$ lower than that obtained with mooring data, with an amplitude of $0.9 \mathrm{~Sv}$. Both harmonics explain $\sim 51 \%$ of the daily Tyuc-proxy subinertial variance (Table 1). This is perhaps not surprising considering the proxy is obtained from regression parameters based on 120-day averages (Athié et al. 2015) and filters out some of the variability. In addition, harmonic analysis of the 78 months of Tyuc data, including the anomalous period of 1999-2001 [see Athié et al. (2015), for more information about the anomalous low transport during the 1999-2001 period] yields an amplitude of the annual and semiannual components of 2.4 and $1.4 \mathrm{~Sv}$, respectively. They only explain $\sim 18 \%$ of the subinertial variance due to the anomalous 1999-2001 period. The seasonal cycle calculated for the latter period alone (i.e., 19 months, not shown) shows notable differences, particularly very small amplitude of the annual component $(<0.1 \mathrm{~Sv})$. Finally, the analysis of 23-yr Tyuc-proxy series also yields a dominant annual contribution $(2.1 \mathrm{~Sv})$ and a small semiannual component $(0.7 \mathrm{~Sv})$, comparable to the calculation for Tyuc, which represents $\sim 36 \%$ of the Tyuc-proxy variance (Table 1 ).

The monthly climatology of Tyuc derived from the mooring data for the periods $2010-11$ and 2012-13, 


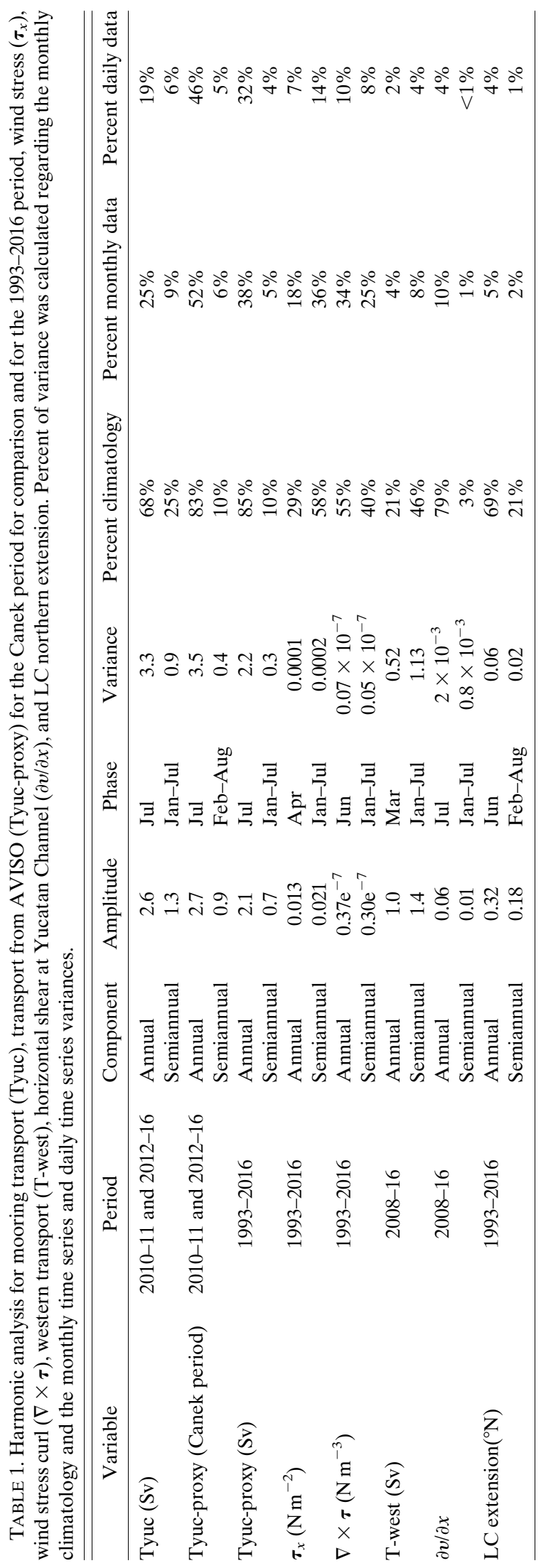

shows an annual structure with a maximum increase in July of $31.4 \mathrm{~Sv}$ (Fig. 3a, anomaly in July of $+3.9 \mathrm{~Sv}$ ), minimum of $24.9 \mathrm{~Sv}$ in March (anomaly of $-2.6 \mathrm{~Sv}$ ) and is well represented by the seasonal cycle derived from the two harmonics. The 25 th and the 75 th percentiles for each month (boxes in Fig. 3a) show that the increase in summer is significantly different from the minima in autumn and spring. It is important to consider that, on average, there are only 5 data points per month, a limitation of the dataset that renders large uncertainties to the results. However, up to now, this is the best estimate that can be made from continuous direct measurements in the Yucatan Channel.

The monthly climatology for the Tyuc-proxy was calculated considering the same dates corresponding to the mooring measurement periods (Fig. 3b). Maximum transport of $29.6 \mathrm{~Sv}$ corresponds to July (anomaly of $+3.1 \mathrm{~Sv}$ ) and minimum in November of $23.9 \mathrm{~Sv}$ (anomaly of $-2.6 \mathrm{~Sv}$ ). Its annual behavior (phase) is essentially the same if the monthly climatology is computed using the full transport-proxy time series (19932016, Fig. 3c). Some differences are observed between the Tyuc and Tyuc-proxy climatologies. In JanuaryMarch, Tyuc decreases and has minimum transport in March, whereas Tyuc-proxy slightly increases during the same period and its minimum transport is in November. Given the large spread in monthly values and the uncertainties due to the limited number of data per month, it is difficult to determine how significant this difference is. However, we still believe the proxy captures the main features of the seasonal behavior of transport in the Yucatan Channel. The 23-yr transport proxy (Fig. 3c) depicts a maximum transport in July of $29.1 \mathrm{~Sv}$ (anomaly of $+2.6 \mathrm{~Sv}$ ), and minimum in November of $24.8 \mathrm{~Sv}$ (anomaly of $-1.8 \mathrm{~Sv}$ ), also with high variability. The large spread in monthly mean values is caused by substantial interannual and intraseasonal variability (see below) that complicates the estimation of a robust seasonal climatology, which needs a very long time series for a low-error estimation (Meinen et al. 2010; Liu and Weisberg 2012).

These results contrast with the ship-based cross sections of current measurements at the Yucatan Channel $(0-1000 \mathrm{~m})$ complemented with HYCOM model deep flows from Rousset and Beal (2011). They found a pronounced symmetric bimodal (semiannual) behavior with winter and summer maxima of the same amplitude $(\sim 2.5 \mathrm{~Sv})$, although they do mention that the winter maximum in their calculations is not robust due to uneven temporal sampling during their observational period (2001-06). The monthly climatology produced by their model results has a dominant annual behavior with a small semiannual contribution in better 

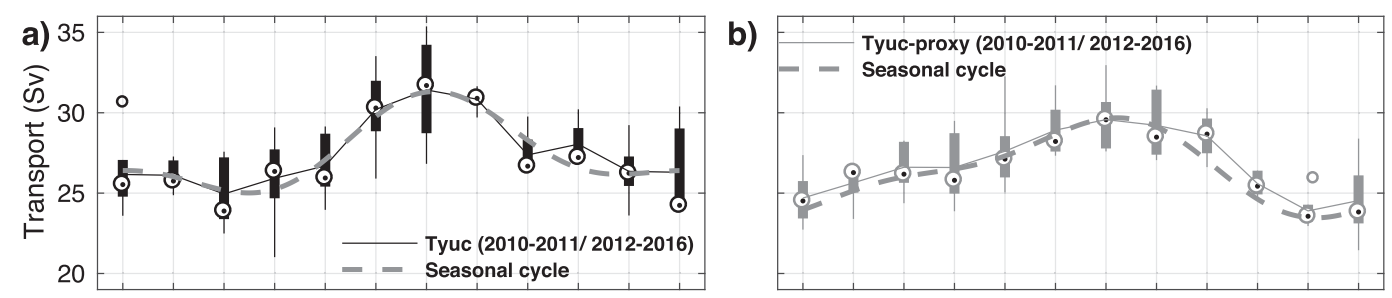

Jan Feb Mar Apr May Jun Jul Aug Sep Oct Nov Dec
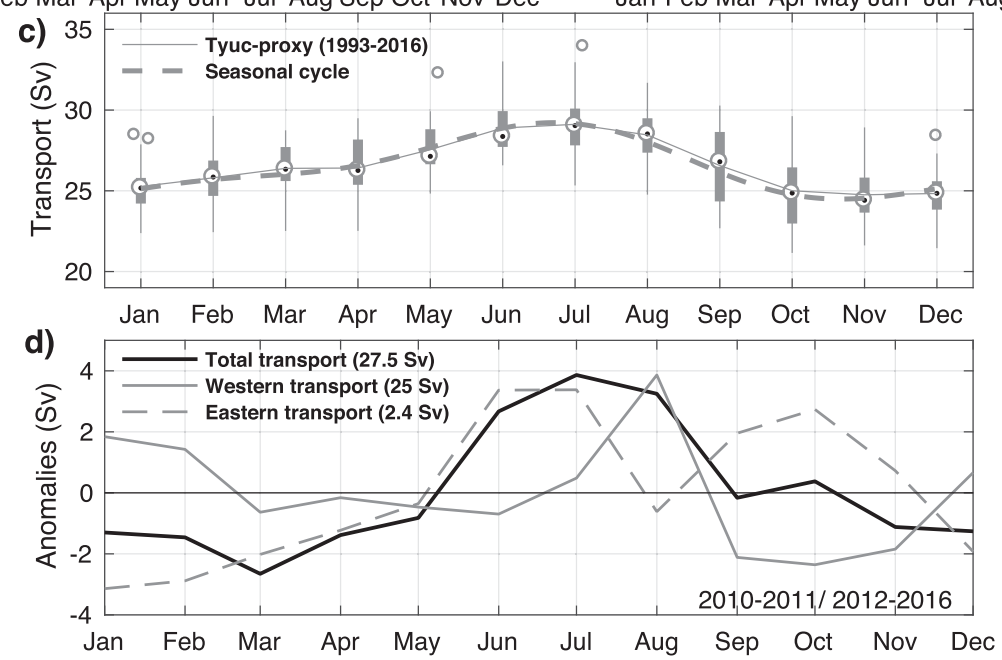

FIG. 3. Monthly climatology of transport at Yucatan Channel. (a) Mooring data, Tyuc, in black (59 months), (b) Tyuc-proxy of AVISO in gray for the same period as in (a), and (c) Tyuc-proxy of AVISO between 1993 and 2016; the thick gray dashed line in (a)-(c) indicates the seasonal cycle for each case (see Fig. 2). (d) Transport anomalies from mooring data (the 59 months), considering the whole Yucatan Channel (black), transport calculated west of $85.6^{\circ} \mathrm{W}$ (gray), and transport calculated east of $85.6^{\circ} \mathrm{W}$ (dotted gray). Continuous lines in (a)-(c) indicate the average values, dots indicate the median, boxes are the 25 th and 75 th percentiles, vertical lines are the minimum and maximum values, and circles indicates the outliers.

agreement with our results and those of CO. However, the amplitude of the summer maximum reported by $\mathrm{CO}$ and Rousset and Beal (2011) is about 1.5 and $2 \mathrm{~Sv}$, respectively, which is lower than the $3.3 \mathrm{~Sv}$ observed in July from mooring data (Fig. 3).

The seasonal cycle of Florida transport (between Florida and Cuba), from 4-yr continuous mooring measurements (Candela et al. 2019), also has a dominant annual component with an amplitude of 3.1 and $1.0 \mathrm{~Sv}$ for the semiannual component, in agreement with the amplitude of the seasonal cycle obtained here for the Yucatan Channel (Table 1). Further north in the Florida Straits (near $27^{\circ} \mathrm{N}$ submarine cable transport data), the annual and semiannual component contributions to the seasonal cycle can vary depending on the period considered (Meinen et al. 2010). The maximum seasonal amplitude was only $\sim 1.5 \mathrm{~Sv}$ between 1982 and 2007 and $\sim 1.0$ Sv between 1990 and 2017. Moreover, the contribution of both components only accounts for $8 \%$ of the total variance for the cable transport (estimated by us from the cable data, not shown). The difference between the amplitude of the seasonal cycle in the Yucatan
Channel and the Florida-Cuba section with the Florida cable measurements, suggests that the contribution of the flow from other channels can be important, particularly from the Old Bahama Channel (Candela et al. 2019). This contrasts with the Rousset and Beal (2011) results that suggest the monthly transport climatology in the Yucatan Channel and Florida Strait at $26^{\circ} \mathrm{N}$ have very similar behavior. Interestingly, the pronounced semiannual component reported in Rousset and Beal (2011) is also somewhat at odds with Meinen et al. (2010), who found a weak semiannual component in the seasonal cycle of the cable data during a similar period (2000-07).

A noteworthy issue arises when one calculates the transport in the Yucatan Channel at the western and eastern sides of $85.6^{\circ} \mathrm{W}$ separately (Fig. 3d), since they seem to have an inverse or almost compensating behavior not only at seasonal scales, but also at other frequencies (Athié et al. 2015). The transport compensation through Yucatan Channel was first discussed by Abascal et al. (2003), who showed that transport fluctuations are not necessarily associated with maxima in eddy kinetic energy. Analysis of the western Yucatan 
a) Zonal windstress vs Tyuc-proxy

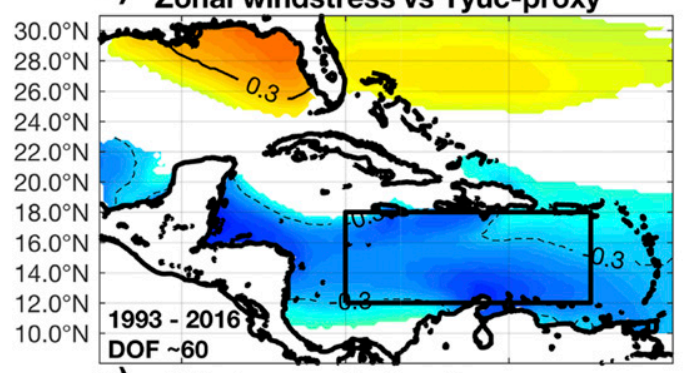

c) Windstress Curl vs Tyuc-proxy

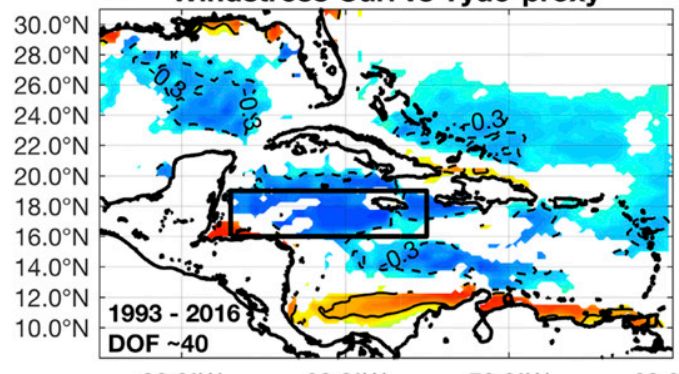

$90.0^{\circ} \mathrm{W}$

$80.0^{\circ} \mathrm{W}$

$70.0^{\circ} \mathrm{W}$

$60.0^{\circ} \mathrm{W} \quad 90.0^{\circ} \mathrm{W}$

b) Zonal windstress vs Tyuc

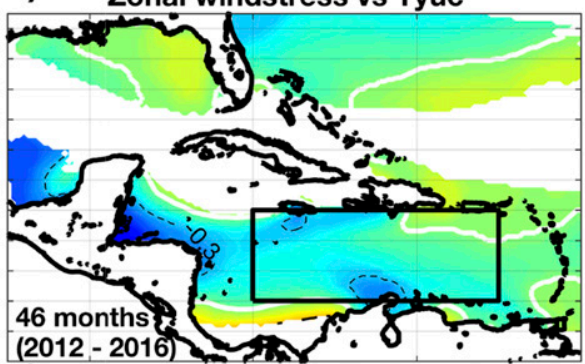

d)

FIG. 4. Maps of correlations between zonal wind stress and (a) monthly Tyuc-proxy (1993-2016) and (b) monthly Tyuc (47 months of continuous series 2012-16), and between wind stress curl and (c) monthly Tyuc-proxy and (d) monthly Tyuc. The wind is leading transport by 1 month (in white regions correlations were not significant at the $95 \%$ confidence level, for the Tyuc-proxy; for Tyuc, the black dashed line shows the $95 \%$ confidence level). The black rectangle indicates the area where zonal wind stress and wind stress curl were averaged for the wind time series used in Figs. 5 and 6.

Channel seasonality is not very clear and presents stronger variability at higher frequencies (2-3 months periods). Moreover, the semiannual harmonic dominates over the annual signal (amplitudes of 1.4 and $1.0 \mathrm{~Sv}$, respectively) with both harmonics explaining $\sim 67 \%$ of the monthly climatology but $\sim 6 \%$ of the daily series variance (Table 1 ); it needs $\sim 4$ harmonics (annual, semiannual, quarterly, and 1.5 months) to approach the observed seasonal cycle (with $r=0.8$ ) at the $95 \%$ level. On the other hand, the seasonal cycle of Tyuc (considering the whole channel) accounts for $93 \%$ of the monthly climatology variance and only required two harmonics (annual and semiannual, see discussion above) to represent the monthly climatology $(r=0.99)$. Hence, the monthly climatology of Tyuc is different from the one considering only the western side of the channel, which basically represents that of the Yucatan Current transport. Although the western part carries most of the mean transport in the Yucatan Channel, it is important to notice that the annual and semiannual variability in the western and eastern parts is of similar amplitude.

\section{Seasonal variations related to the wind}

Correlation maps between monthly Tyuc-proxy (1993-2016) and $\left\langle\boldsymbol{\tau}_{x}\right\rangle$, as well as $\langle\nabla \times \boldsymbol{\tau}\rangle$ series at every point of the wind data grid, where angle brackets \langle\rangle indicate monthly averages, were carried out (Figs. 4a,c). Transport series were lagged by one month, determined from cross-correlation analysis. Wind variables, $\left\langle\boldsymbol{\tau}_{x}\right\rangle$ and $\langle\nabla \times \boldsymbol{\tau}\rangle$, are leading Tyuc by one month, particularly at the Northwestern Caribbean, which is in agreement with CO results. Degrees of freedom (DOF) were also estimated at each point of the map to determine the significance of the correlations (Emery and Thomson 2001). Two inverse high-correlation zones are found in the Caribbean, with particularly higher values in summer (not shown). First is the region in the southern Caribbean, where $\left\langle\boldsymbol{\tau}_{x}\right\rangle$ is significantly correlated with the Tyuc-proxy (Fig. 4a, highest negative correlation of -0.46 ; which is negative due to the negative sign of the Easterlies; DOF are $\sim 60$ in this zone). This area has been previously identified as the Caribbean low level jet (CLLJ) region (Amador 1998; Wang 2007), with changes in the wind probably linked to meridional MADT gradients (Alvera-Azcárate et al. 2009; CO). Second is the region located mainly in the Cayman Sea, where $\langle\nabla \times \boldsymbol{\tau}\rangle$ is significantly correlated with the Tyucproxy (Fig. 4c, highest negative correlation of $\sim-0.50$, with DOF $\sim 40$ in this zone). It is interesting that similar behavior and values of the negative correlation in the Caribbean result if one only uses the 46 months of 
longest continuous Tyuc measurements (from October 2012 to July 2016; Figs. 4b and 4d, with transport also lagged by 1 month), although the correlation values are mostly nonsignificant, due to the small number of DOFs produced by the short time series (significant values are inside the black dashed line). Tyuc has a maximum negative correlation of $\sim-0.34$ with $\left\langle\boldsymbol{\tau}_{x}\right\rangle$ (Fig. 4b), while $\langle\nabla \times \boldsymbol{\tau}\rangle$ and Tyuc have correlations at the Cayman Sea with maxima of -0.54 (Fig. $4 d$; with DOF $\sim 20$ in this zone).

These zones of high correlation were also identified by Chang and Oey (2012, their Fig. 2) who built indices based on spatially averaging $\left\langle\boldsymbol{\tau}_{x}\right\rangle$ and $\langle\nabla \times \boldsymbol{\tau}\rangle$ over a single region $\left(87^{\circ}-80^{\circ} \mathrm{W}, 15^{\circ}-22^{\circ} \mathrm{N}\right)$. Here we decided to compute wind-forcing indices in two different zones following the two areas of highest correlation in the Caribbean (Fig. 4). Hence, $\left\langle\boldsymbol{\tau}_{x}\right\rangle$ was spatially averaged within $\left(80^{\circ}-65^{\circ} \mathrm{W}, 12^{\circ}-18^{\circ} \mathrm{N}\right)$, and $\langle\nabla \times \boldsymbol{\tau}\rangle$ was averaged within $\left(87^{\circ}-75^{\circ} \mathrm{W}, 16^{\circ}-19^{\circ} \mathrm{N}\right)$. The results do not change significantly if one uses the same area as Chang and Oey (2012). The monthly time series, monthly climatology, and spectral analysis of these wind-forcing indices are presented in Figs. 5 and 6.

The monthly climatologies of $\left\langle\boldsymbol{\tau}_{x}\right\rangle$ and $\langle\nabla \times \boldsymbol{\tau}\rangle$ depict strong seasonal behavior (Figs. 5b,c), although they are slightly different. The seasonal cycle of $\left\langle\boldsymbol{\tau}_{x}\right\rangle$ is mainly biannual, with amplitude of $0.021 \mathrm{~N} \mathrm{~m}^{-2}$ (Table 1), which is almost twice the annual component $\left(0.013 \mathrm{~N} \mathrm{~m}^{-2}\right)$, while annual and semiannual components of the seasonal cycle of $\langle\nabla \times \boldsymbol{\tau}\rangle$, are of similar amplitude, $0.37 \times$ $10^{-7}$ and $0.30 \times 10^{-7} \mathrm{~N} \mathrm{~m}^{-3}$, respectively (Table 1$)$. The seasonal cycles of $\left\langle\boldsymbol{\tau}_{x}\right\rangle$ and $\langle\nabla \times \boldsymbol{\tau}\rangle$ (annual + semiannual harmonics) in both cases represent $\sim 60 \%$ of the monthly variance, but only $\sim 20 \%$ of the daily variability (Table 1 ). Both variables have maximum negative strength in summer (negative values mean easterly intensifications and anticyclonic strengthening in June and July) that corresponds to the maximum transport observed at the Yucatan Channel (black lines). In winter, $\left\langle\boldsymbol{\tau}_{x}\right\rangle$ has a second easterly intensification between December and February. Confidence intervals were calculated using the bootstrap method that shows that both easterly maxima in $\left\langle\boldsymbol{\tau}_{x}\right\rangle$ are significantly different from the minima in spring and autumn. Note that $\langle\nabla \times \boldsymbol{\tau}\rangle$ has only a minor anticyclonic intensification in February (Figs. 5a,c).

The statistics of $\left\langle\boldsymbol{\tau}_{x}\right\rangle$ and $\langle\nabla \times \boldsymbol{\tau}\rangle$ presented in Figs. 5b and $5 \mathrm{c}$ show a large spread of the monthly values, suggesting other frequency signals are important, particularly interannual variations. For example, the monthly mean values of Cayman Sea easterly wind forcing during the 2000-06 period reported in Rousset and Beal (2011, also found in our data) depict stronger easterlies in fall rather than summer, somewhat opposite to our monthly wind climatology since the wind stress curl remains maximally anticyclonic in summer and cyclonic in fall. There is also the low frequency variability in the Caribbean documented by Jouanno and Sheinbaum (2012) and the peak of $\sim 4.5$ years that appears in the Caribbean MADT spectrum, computed by AlveraAzcárate et al. (2009).

Given the complex dynamics and high variability of the Caribbean Sea-Gulf of Mexico wind and current system, it is important to look at year-to-year variations to determine if the wind-Tyuc deterministic relation proposed by $\mathrm{CO}$ still applies. The full-length monthly time series of Tyuc and negative $\langle\nabla \times \boldsymbol{\tau}\rangle$ at the Cayman Sea shows they both increase during summer, with a much less clear winter connection (Fig. 5d, with $\langle\nabla \times \boldsymbol{\tau}\rangle$ multiplied by -1 to have a direct comparison with the Tyuc intensifications). The correlation between $\langle\nabla \times \boldsymbol{\tau}\rangle$ and Tyuc, putting both periods together (2010-11 and $2012-16)$ is -0.47 , which is significant at $95 \%$, with $\langle\nabla \times \boldsymbol{\tau}\rangle$ leading Tyuc by one month (Fig. 5d). Monthly time series of Tyuc-proxy and $\langle\nabla \times \boldsymbol{\tau}\rangle$ for the 1993-2016 period (Fig. 5e) depict a clear intensification in the summer of nearly every year, wind stress curl leading by $\sim 1$ month (tick marks correspond to the month of July of each year) and a correlation of -0.45 (95\% significant). Their amplitudes, however, are not always consistent over the 23 years in the sense that one would expect both series to grow or decrease together (e.g., stronger anticyclonic curl means stronger transports according to the $\mathrm{CO}$ mechanism). In our results only in 14 of the 23 years, that is, $\sim 60 \%$ of the cases, Tyuc-proxy and $\langle\nabla \times \boldsymbol{\tau}\rangle$ have similar increments at seasonal scales during summer. Strong interannual variations in amplitude are present in the series (Fig. 5e); compare, for example, the summers of 1993-94, 2014-15 with those of 1998, 2000, 2003, and even some years where the anomalies have opposite sign $(2009,2012)$.

The relative increase of $\langle\nabla \times \boldsymbol{\tau}\rangle$ and Tyuc in winter vary from one year to another, not only in amplitude but also in the month that they occur (Fig. 5d). Also, Tyuc does not reach positive anomalies in two of the five winters available in the observations (2014-15). In the Tyuc-proxy series (Fig. 5e), a very small increase is observed in several winters, but anomalies reached positive values only in half of the 24 winters. This higher uncertainty in the winter connection between wind, Yucatan Channel transport, and LC response (the latter discussed in section 5 below) is consistent with the analysis of Hall and Leben (2016) using a longer series (30 years) of prealtimetric, altimetric, and reanalysis data. They found more differences in the date of LCE releases during winter and not 

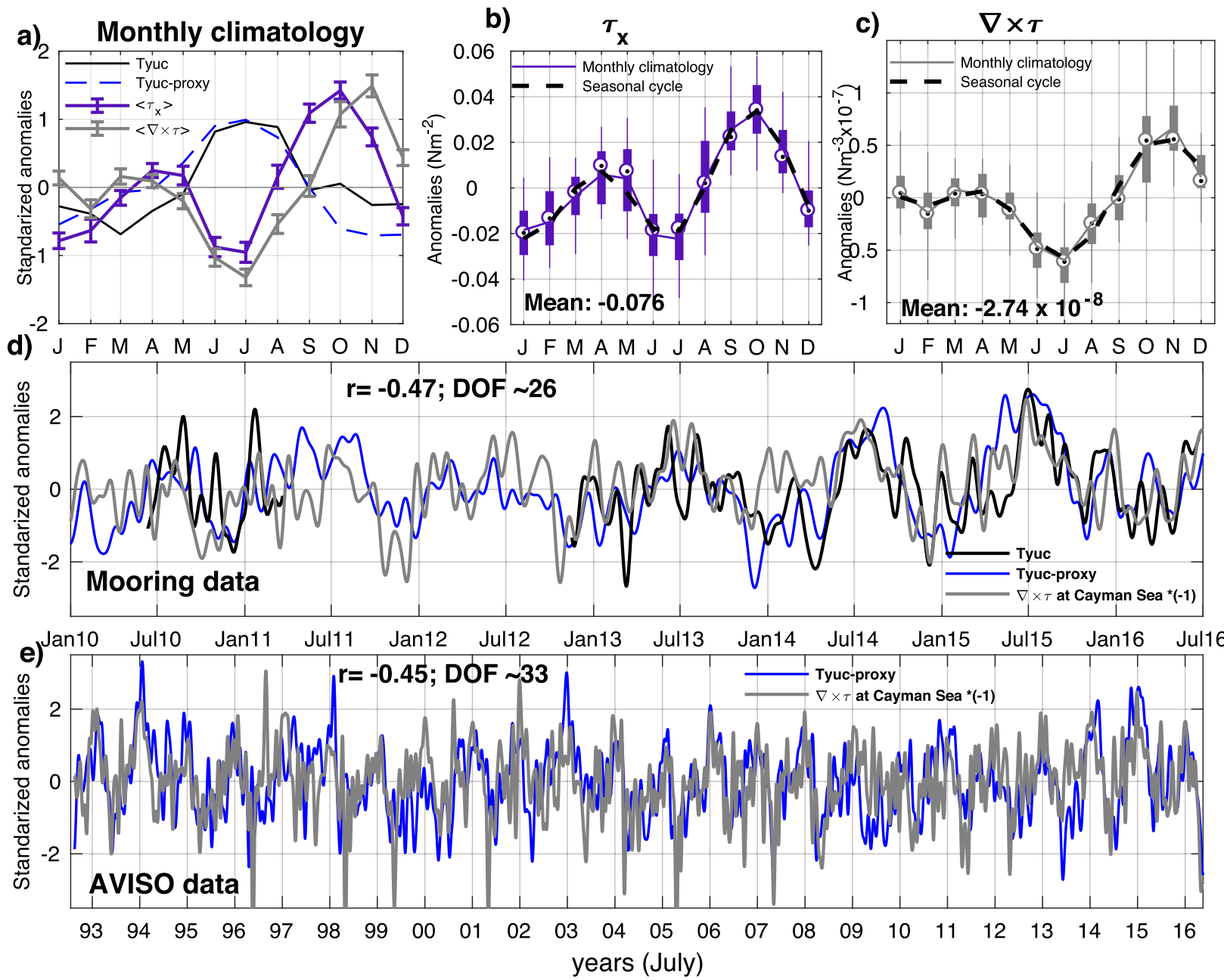

FIG. 5. (a) Monthly climatology of Tyuc (solid black), Tyuc-proxy (dashed blue), zonal wind stress (purple), and wind stress curl (gray). Monthly climatology of (b) zonal wind stress and (c) wind stress curl (the respective mean values are indicated and their seasonal cycles are indicated in black). The line indicates the average values, dots indicate the median, boxes are the 25 th and 75 th percentiles, and vertical lines are the minimum and maximum values. (d) Monthly time series of Tyuc (black), Tyuc-proxy (blue), and wind stress curl (gray, multiplied by -1), where correlation values and degrees of freedom (DOF) between Tyuc and wind stress curl are indicated for each measuring period. (e) Monthly time series (23 years) of Tyuc-proxy (blue) and wind stress curl (gray, multiplied by -1 ; tick marks correspond to the month of July of each year). Series are normalized anomalies (standard deviations are $0.024 \mathrm{~N} \mathrm{~m}^{-2}$ and $4.51 \times$ $10^{-8} \mathrm{~N} \mathrm{~m}^{-3}$ for zonal wind stress and wind stress curl, respectively). Wind variables considered between 1993 and 2016 were averaged over the areas indicated in Fig. 4.

enough statistical confidence to make it a preferred eddy release season in contrast with the robust result obtained for summer.

\section{Variability of the Yucatan Channel transport, Yucatan Current dynamics, and LC extension}

Spectral analyses of the daily $\nabla \times \tau(1993-2016)$ series, mooring Yucatan Channel transport (Tyuc; 2012-16), and Tyuc-proxy (1993-2016) are shown in Figs. 6a-c, respectively. In addition, the eddy kinetic energy (EKE) spectra were calculated from the mooring (optimally interpolated) surface velocities (black line in Fig. 6d) and AVISO surface geostrophic currents (Fig. 6e) for comparison. A spatially averaged surface spectrum is obtained integrating the spectra at each point along the Yucatan section and dividing by the section's length. We also computed a full section averaged spectrum of the mooring interpolated velocities obtained by integrating the spectra at each point over the section and dividing it by the total area (gray line in Fig. 6d). The $\nabla \times \tau$ spectrum is dominated by semiannual and annual frequencies, as well as highfrequency variability (between 10 and 15 days; Fig. 6a). 

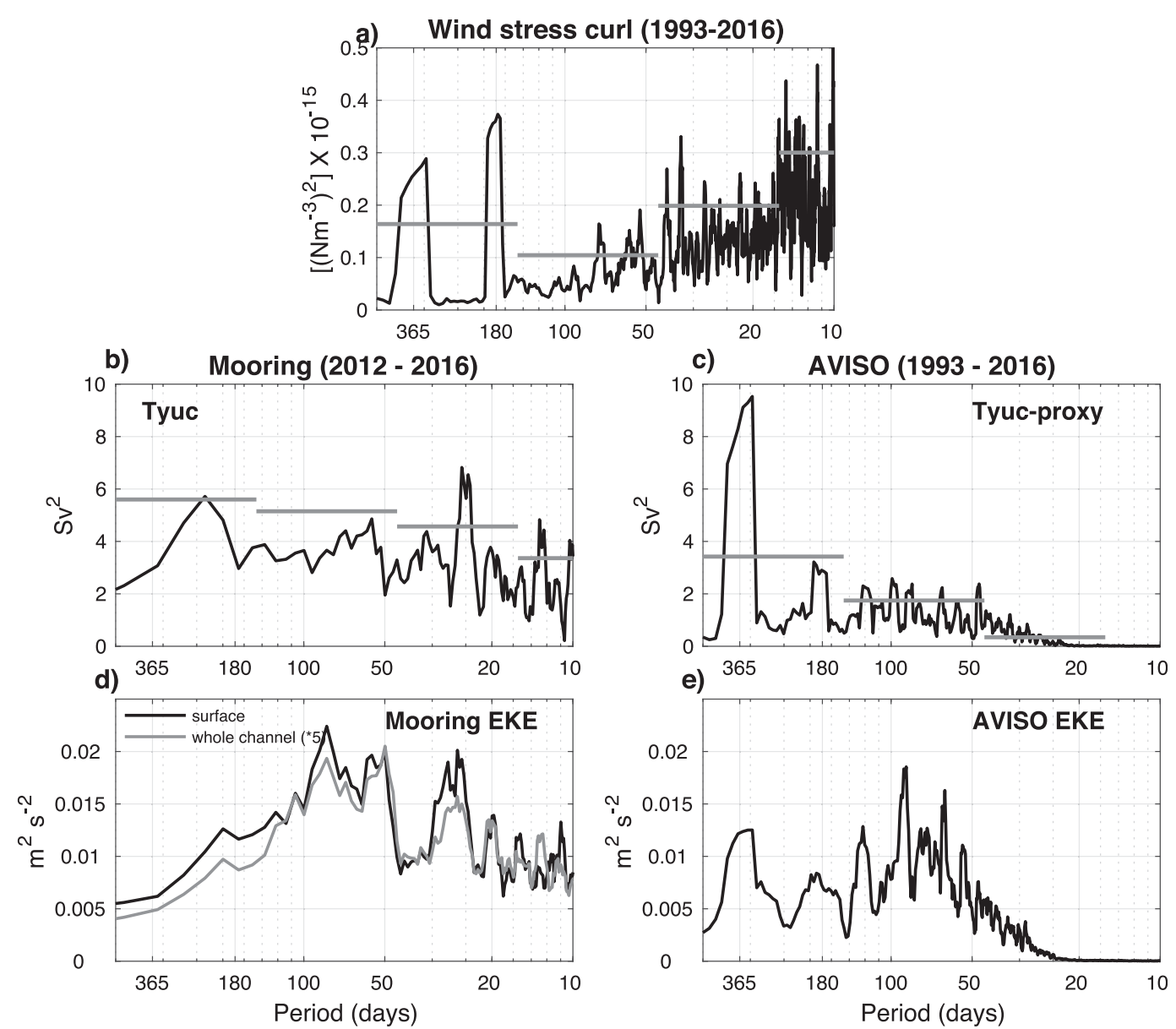

FIG. 6. Variance-conserving power spectra of (a) wind stress curl (1993-2016; averaged over the area indicated in Figs. 4c and 4d), (b) Tyuc (47 months of continuous series, 2012-16), (c) Tyuc-proxy (1993-2016), (d) EKE from mooring data (spatially averaged at the surface, in black trace, for comparison to AVISO calculation, and averaged in the full section, in gray trace), and (e) EKE from AVISO data (1993-2016). The multitaper spectra are built with 3.5 tapers.

Tyuc shows the highest peaks at $\sim 25$ and $\sim 15$ days, but also high variance at other frequencies, and a peak near 230 days at low frequencies (Fig. 6b). It is important, however, to consider that only $\sim 3.5$ years (from October 2012 to August 2016) of Tyuc continuous series were considered for computing its spectrum. The spectrum of 23 years of Tyuc-proxy series has a strong annual peak, with much lower energy at the semiannual frequency (Fig. 6c). For periods shorter than 120 days, energy is quite low due to the calculation of the proxy itself (Athié et al. 2015). Interestingly, the spectrum of EKE at the surface from either mooring (Fig. 6d, black line) or AVISO geostrophic velocities (Fig. 6e), have the highest energy at periods between 50 and 100 days, with an additional peak at 35 days in the mooring series. Similar results were obtained with the EKE spectrum integrated over the whole water column with mooring data (Fig. 6d, gray line). At these frequencies (50-100 days), the $\nabla \times \tau$ series have lower energy than at seasonal or high-frequency scales (periods $<20$ days), suggesting that the 50-100-day band is probably more related to instabilities and cyclonic/anticyclonic eddies reaching the Yucatan Channel than direct wind forcing, possibly implying some compensation in transport, as the relatively reduced transport spectra in this band suggests.

The transport efficiency index I (defined in section 2), is an indicator of the significance of transport compensation in the channel produced by the out of phase westeast normal flows in the section and must approach zero if there is compensation. Conversely, values of index $I$ closer to one, represent efficient transport fluctuations or flows that are more spatially uniform and in phase. During the 2012-16 period of continuous mooring observations, $I$ generally remains with values below 0.15 , with only two events where $I$ reached 0.17 (Fig. 7, series were 10-day filtered for clarity), in agreement with the 1-yr mooring series analyzed by Abascal et al. (2003) for the 1999-2000 period. This result indicates there is large 

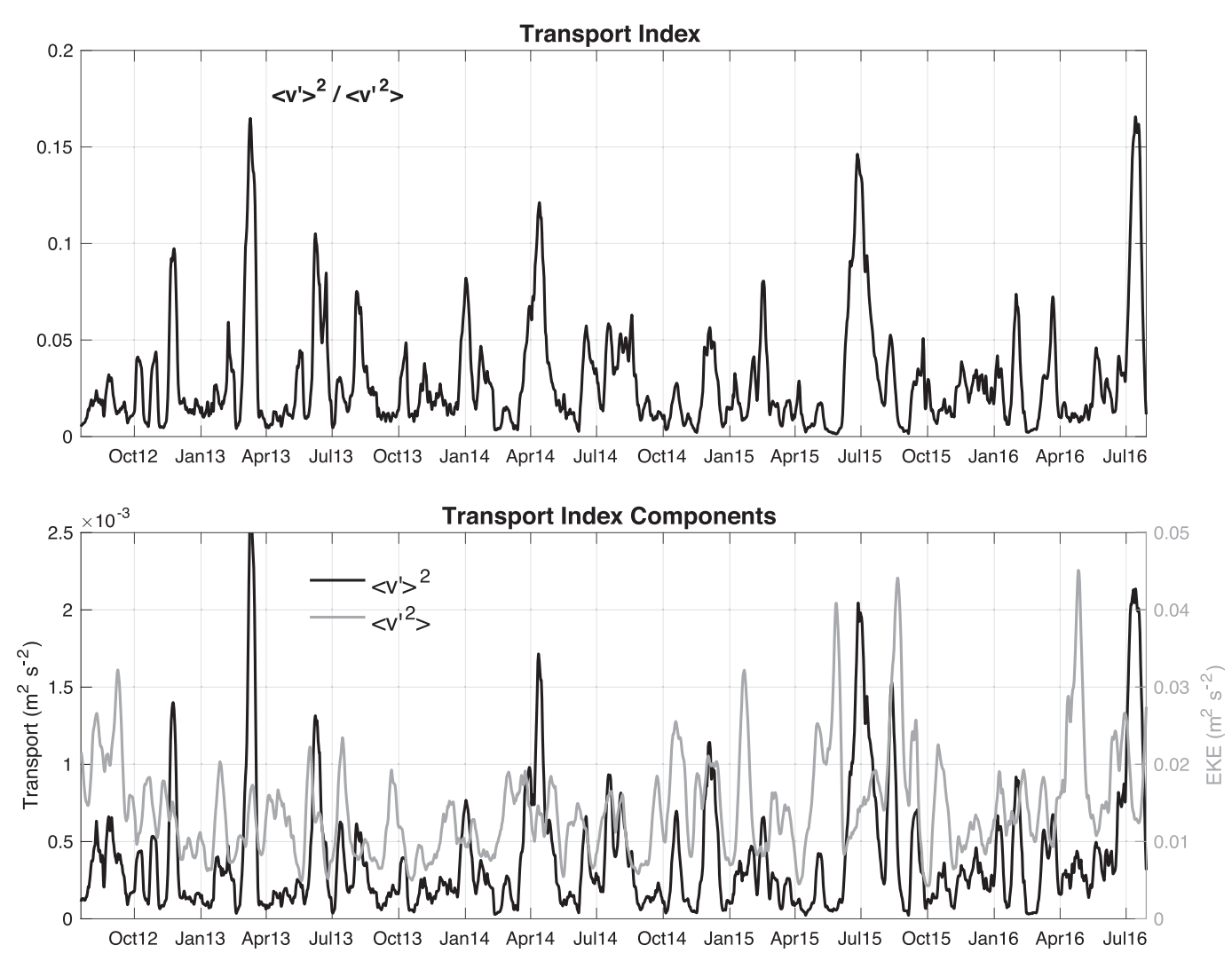

FIG. 7. (top) Transport index $I$. (bottom) Time series of transport index components: $\left\langle v^{\prime}\right\rangle^{2}$ indicates the net transport pulses (left axis in black); $\left\langle v^{\prime 2}\right\rangle$ indicates the energy pulses (right axis in gray). Series were 10-day filtered for clarity.

compensation of the flows through the channel and high-energy events of low-transport signal, consistent with the presence or propagation of coherent eddies through the channel (either cyclones or anticyclones, e.g., Richardson 2005; Alvera-Azcárate et al. 2009; Jouanno et al. 2009; Athié et al. 2012) or other compensating mechanisms (Rousset and Beal 2011; Mildner et al. 2013; Kourafalou et al. 2017). However, when comparing the two components of $I$ there are periods in which transport pulses are dominant, some with low energy and some where both components (energy and transport) are important. They could indicate (uncompensated) Yucatan Channel intensifications and meanders, full-section spatially coherent perturbations, or partial eddy crossings. Differences in vertical structure across the channel may also be important (Bunge et al. 2002; Sheinbaum et al. 2016). The cause of these dissimilar perturbations remains uncertain, and we only provide some discussion about them in the final section.

The monthly climatology of relative vorticity estimated from AVISO geostrophic velocities and the horizontal shear from mooring data $(\partial v / \partial x)$ at the Yucatan Channel are shown in Fig. 8. The reason for this calculation is that the $\mathrm{CO}$ mechanism also suggests a strong correlation between Yucatan Current relative vorticity, LC northward extension, and transport. There is a relative increase of vorticity between June and August, in agreement with the transport increase (Tyuc); however, there is also intense variability of 2-3-month periods in both $\partial v / \partial x$ from moorings and vorticity from AVISO (Fig. 8a). The seasonal cycle (i.e., annual and semiannual components) of $\partial v / \partial x$ from mooring data is mainly annual. Due to its high-frequency variability, it represents $\sim 80 \%$ of the variance in the monthly climatology but less than $5 \%$ of the variance in the daily data (Table 1).

Monthly low-pass series of $\partial v / \partial x$ calculated from moorings (Fig. 8b, blue line) were compared with the monthly averaged Tyuc (black line) and transports estimated only for the western side of the channel (gray line; the period between 2008 and 2016; see Fig. 1 for reference). Correlation between $\partial v / \partial x$ and the western transports for the 2008-16 period is not high but significant ( $r=0.50$; with 55 DOF) and no significant correlation exists between $\partial v / \partial x$ and Tyuc $(r=0.22)$. Again, looking at particular periods, one can see that vorticity, Tyuc, and Tyuc-proxy all tend to increase during the summer of almost every year. Higher-frequency ( $\sim 3$ months) 

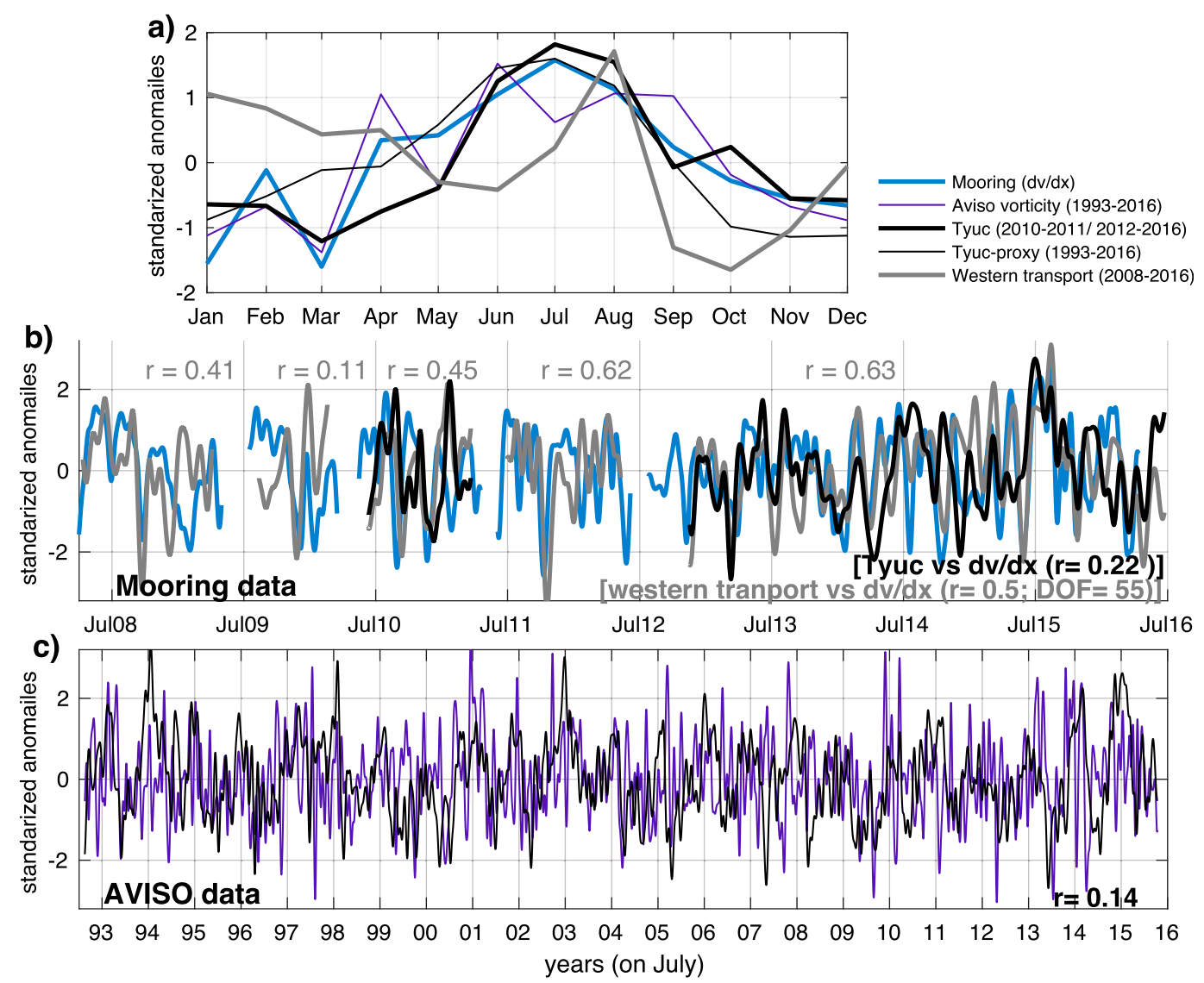

FIG. 8. (a) Monthly climatology of horizontal shear velocity from mooring measurements (59 months; blue line), AVISO relative vorticity $\zeta / f$ at the Yucatan Channel (1993-2016; purple line), Tyuc (59 months; thick black line), Tyuc-proxy (1993-2016; thin black line) and western transport from mooring at Yucatan Channel (west of 85.6 ${ }^{\circ} \mathrm{W}$, see Fig. 1; 2008-16, in gray line). (b) Monthly low-pass time series of horizontal shear velocity at Yucatan Channel, Tyuc, and western transport; correlations for the measurement periods (western transport) are indicated in the upper part of the figure. (c) Monthly low-pass relative vorticity at the Yucatan Channel and Tyuc-proxy (tick marks correspond to the month of July of each year). Correlation values indicated. All are standardized anomalies.

variability appears to be stronger than the seasonal signal in both vorticity and western transport. Still, there are specific periods where $\partial v / \partial x$ and the western transport have simultaneous peaks (e.g., August 2011; January 2013 or May-July 2015), but this does not happen at other times. The comparison between relative vorticity calculated from AVISO data and Tyuc-proxy (Fig. 8c, monthly data) also shows certain periods of agreement and simultaneous peaks, suggesting some connection between these variables too (particularly in summer). Nevertheless, the correlation between these two variables using the full time series is nonsignificant (0.14), and does not show a close connection or high predictability throughout the study period even at seasonal scales as suggested by $\mathrm{CO}$.

The monthly climatology of LC northward extension (23 years) indicates some agreement with the Tyuc and Tyuc-proxy climatologies to the extent that all have maxima between June-August and lower values in fall (Fig. 9a, Table 1). The small decrease in LC northward extension in July is probably associated with eddy separations from the LC, which produces a decrease in all the LC metrics (Leben 2005). LC eddy detachments and therefore LC extension involve many processes including Loop Current frontal eddies (LCFEs) of different characteristics, instabilities, interaction with topography, etc. (e.g., Le Hénaff et al. 2012; Sheinbaum et al. 2016; Garcia-Jove et al. 2016; Hamilton et al. 2016, Jouanno et al. 2016). Our goal here is only to test the $\mathrm{CO}$ mechanism that relates LC extension with wind forcing, transports, and Yucatan Current vorticity.

Cross correlation of monthly time series shows that LC northern intrusions are significantly but weakly correlated ( $r=0.42$; with $53 \mathrm{DOF}$ ) with the western transport calculated from moorings (2008-16 period), with transport leading LC extension by $\sim 1$ month 


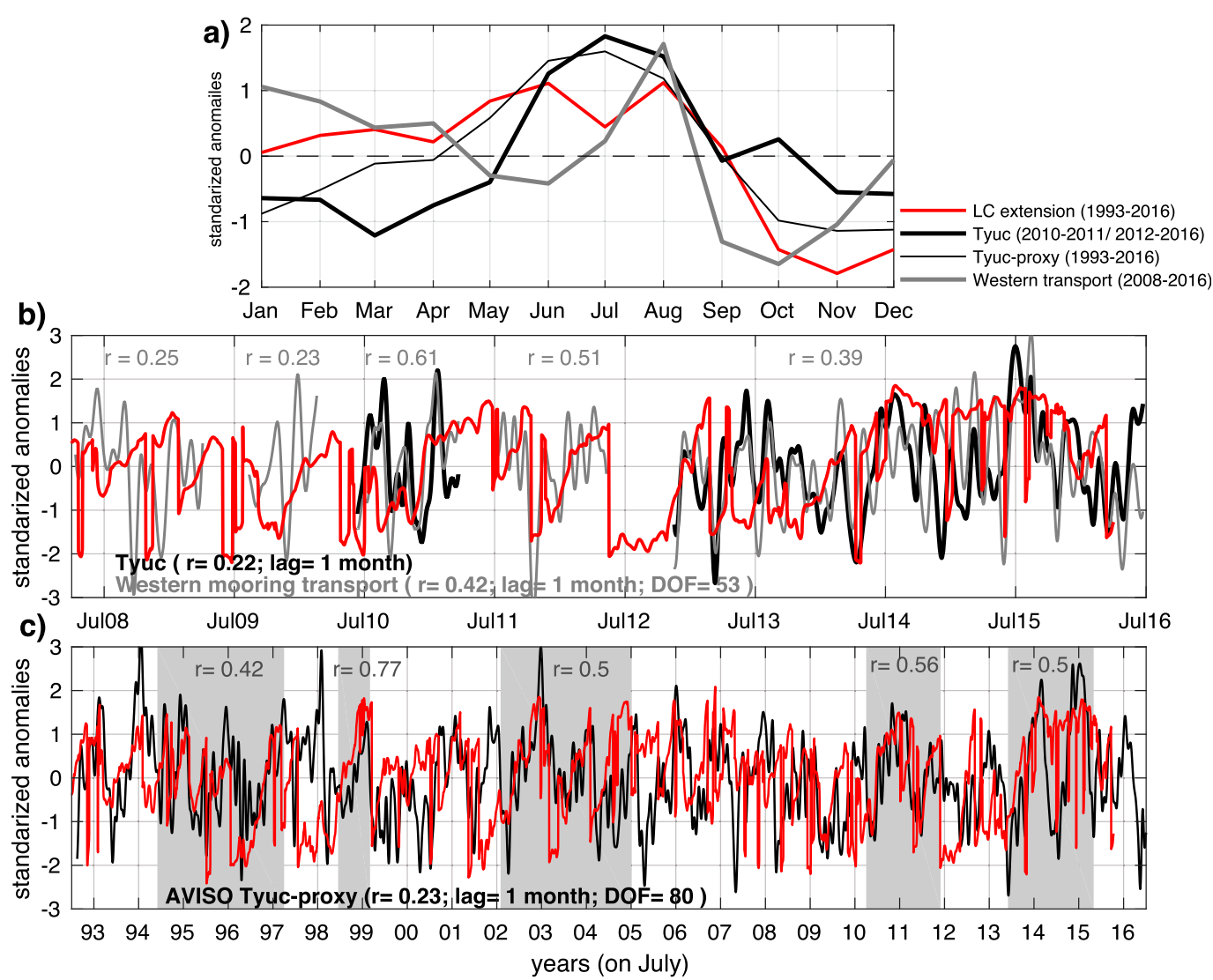

FIG. 9. (a) Monthly climatology of LC northern boundary (red line), Tyuc (59 months, black thick line), Tyucproxy (1993-2016; black thin line), and western transport from mooring at Yucatan Channel (west of 85.6 $6^{\circ} \mathrm{W}$, see Fig. 1; 2008-16; gray line). (b) Monthly low-pass data of Tyuc, western transport, and LC northern boundary; correlations between the western transport and LC extension during the measurement periods are indicated in the upper part of the figure. (c) Monthly data from AVISO: Tyuc-proxy and Loop Current northern boundary (tick marks correspond to the month of July of each year); correlations at particular periods (in gray) are indicated in the upper part of the figure. Maxima correlation values and corresponding lags are indicated. All are standardized anomalies.

(Fig. 9b); stronger visually evident correlation only occurs at specific periods. Furthermore, correlations are nonsignificant when considering monthly averaged transports through the whole channel, either from mooring observations (Tyuc, $r=0.22$ ) or from AVISO monthly series (Tyuc-proxy, $r=0.23$; Figs. $9 \mathrm{~b}$ and $9 \mathrm{c}$ ).

Similar to the case between vorticity and transport, a more detailed analysis reveals Tyuc-proxy intensifications and LC northern extension do seem to be correlated at particular periods and mainly in summer (see correlation values for specific periods in Figs. $9 \mathrm{~b}$ and $9 \mathrm{c}$ ). Notice years with particularly low summer transports such as 2000, 2004, 2009, 2010, and 2012 with short LC extension but also in the years 1998, 2002, 2008, and 2013 with high summer transports but short LC extension. In summary, our analysis suggests that the connection between LC extension, Yucatan Channel transport, and Yucatan Current vorticity is not straightforward and not as clear cut as suggested by the $\mathrm{CO}$ mechanism, which implies a high positive correlation between all these variables. Our main conclusion is that such a relationship is only valid during some periods (particularly in summer), but opposite or nonexistent on many other occasions, which makes the overall correlation between the series very low or not significant.

Further evidence that western and full Yucatan Channel transports contain different dynamic information is obtained from correlation maps between monthly MADT data and transports at the Yucatan Channel (Fig. 10). These correlations have different spatial structures depending on whether the whole channel transport is considered (Tyuc or Tyuc-proxy; Figs. 10a and $10 \mathrm{~b}$ ) or just the transport at the western side of the channel (from moorings, Fig. 10c).

The highest correlation between Yucatan Channel transports (Tyuc or Tyuc-proxy) and MADT (Figs. 10a,b) 


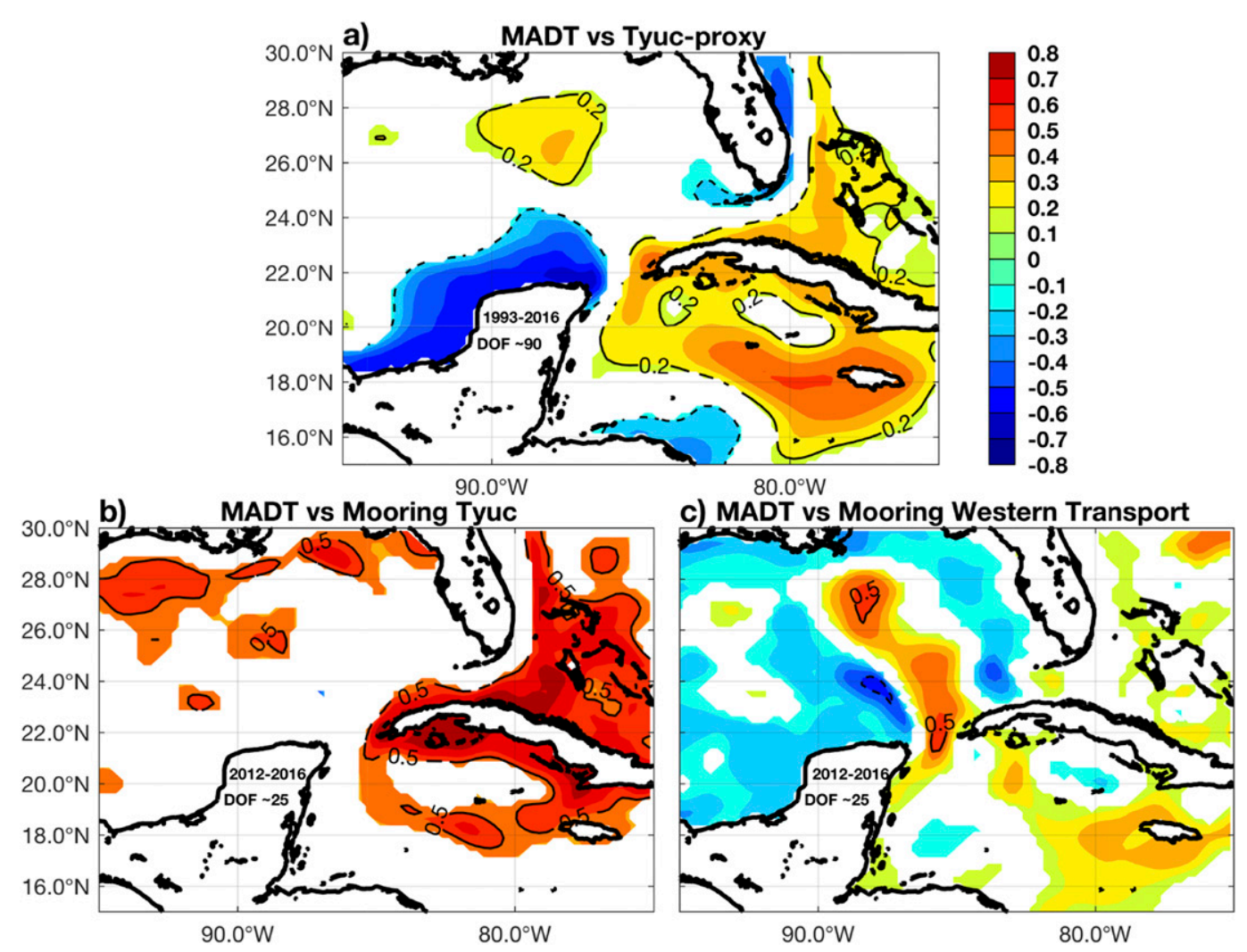

FIG. 10. Maps of correlations between monthly transport at the Yucatan Channel and MADT from AVISO. (a) Tyuc-proxy from AVISO (1993-2016), (b) mooring total-channel transport (Tyuc; 47 months of continuous series 2012-16), and (c) western-channel transport from moorings (47 months of continuous series 2012-16). In white regions correlations were not significant at the $95 \%$ confidence level, for the Tyuc-proxy; for Tyuc, the black dashed line shows the $95 \%$ confidence level.

is located around Cuba (significant values are inside the black line), particularly at the eastern Cayman Sea and the Bahamas. Correlations with Tyuc reach 0.7 north and south of Cuba, while those with Tyuc-proxy are significant, between 0.3 and 0.4 in the same area, with no lag in any of these cases. The correlation maps are indicative of surface pressure gradients associated with the main currents in the region, that is, positive (negative) correlations in the north (south) Cayman sea related to the Cayman (Caribbean) Current, positive (negative) correlations in the eastern (western) Yucatan Channel and Florida Straits. High positive correlations around Cuba agree with model results (Lin et al. 2009) and observations (Candela et al. 2019) that suggest changes in transport through Yucatan Channel can be compensated, in the Florida Current outside the GOM, by the flow passing through the channels north of Cuba, particularly the Old Bahama Channel.

The correlation map (Fig. 10c) between MADT and the western-channel transport computed for the period $2012-16$ is quite different from the results in Figs. 10a and $10 \mathrm{~b}$ discussed above. In this case, positive correlations are high in the area of the LC and its extension, with no lag. Together with the negative correlations on the Campeche Bank, the map is consistent with increased cross-shore sea level gradients and enhanced geostrophic transports. Although one could argue there are similarities in the correlation maps of Figs. 10a-c, it is clear that their "centers of action" are different; for example, the high values around Cuba in Figs. 10a and 10b are nearly absent in Fig. 10c. This is also telling us that the eastern Yucatan Channel dynamics responds to other processes and is not just passively responding to the Yucatan Current in the west. Thus, one should be cautious and take the differences between the east and west channel into account when trying to link LC variability with transports into the GoM.

Some of the high correlation regions (e.g., northeastern GoM in Fig. 10) may indicate changes of pressure gradients in those areas related to coastally trapped waves that could impact the transport in the channel, particularly in winter (Jouanno et al. 2016; Weisberg and Liu 2017; Candela et al. 2019), leading to the asymmetry 
between summer and winter. This is probably an indication that the forced and intrinsic variability of the LC is difficult to disentangle, since comparable results are used to support different theories of LC behavior (CO; Lin et al. 2009; Rousset and Beal 2011; Mildner et al. 2013; Weisberg and Liu 2017).

\section{Summary and conclusions}

Most of the work presented here was carried out to test some of the interesting ideas regarding the LC cycle and its seasonal variability put forward by $\mathrm{CO}$. The $\mathrm{CO}$ mechanism suggests strong easterlies (and/or negative wind stress curl) over the Cayman basin lead to increased Yucatan transport, larger LC penetration, and increased Yucatan Current vorticity. Our analysis indicates that such a mechanism appears to be valid only during specific periods and mainly during summer but not in winter, even though the easterly winds in the Cayman Sea also increase in winter. Year to year variability also shows many instances where strong (weak) local winds coincide with low (high) LC extension and Yucatan transport, opposite to the CO mechanism. So the idea of a strong deterministic connection between variations of the easterly winds and LC behavior at seasonal scales should be considered with care, since it fails to hold on several occasions.

The seasonal cycle of the transport across the Yucatan Channel (Tyuc, $\sim 5$ years of mooring data) has a substantial annual harmonic component with an amplitude of $2.6 \mathrm{~Sv}$ and maximum transport in summer; the semiannual component is smaller (amplitude of $1.3 \mathrm{~Sv}$ ) and is responsible for a weak increase in winter (Table 1; Fig. 2). This seasonal variability accounts for $\sim 25 \%$ of the subinertial variance. A 23-yr time series of a transport proxy computed from sea level differences (Tyuc-proxy, see section 2a) yields annual and semiannual components with amplitudes of 2.1 and $0.7 \mathrm{~Sv}$, respectively.

The dominant annual component of the Yucatan transport (both from moorings and the proxy) is somewhat at odds with the zonal wind forcing in the region that has annual and semiannual components of similar amplitude. Although transports and winds appear to be correlated at seasonal scales, with wind forcing leading by 1 month, the low amplitude of the semiannual component suggests there may be other processes besides the changes in zonal winds affecting the seasonal cycle. The failure to establish a clear correlation between forcing, transports, and LC metrics during winter introduces an asymmetry in the LC correlation statistics that remains to be explained. Possible causes of it may be 1) the anticyclonic wind stress curl over the Cayman Sea during winter is weaker than in summer (Fig. 5);
2) northerly winds from cold fronts crossing the region during winter can produce Ekman convergence along the Yucatan coast, downward displacement of the isopycnals, and a weaker slope of the thermocline across the channel reducing the strength of the flow; 3 ) the frontal weather systems during winter may generate coastally trapped waves over the GoM and the Yucatan coast that may affect the transport in Yucatan Channel (e.g., Jouanno et al. 2016). Changes in meridional winds and propagation of coastally trapped waves along the eastern coast of the United States have been considered as possible mechanisms modulating the seasonal cycle of the Gulf Stream (Schott et al. 1988; Anderson and Corry 1985). A similar mechanism could be at play in the Yucatan.

Finally, one cannot neglect the role of eddy activity due to the intrinsic variability of the system. The EKE spectrum over the channel shows a dominant 50-100-day band, which is relatively weak in the wind spectrum (Fig. 6a) and is most likely associated with cyclonic or anticyclonic eddies and meanders. Our results confirm the findings of Abascal et al. (2003) and Athié et al. (2015) who suggest many of these energetic features are associated with weak Yucatan transport anomalies indicating compensation between the western and eastern sides of the channel (Figs. 3d, 6, and 7). Moreover, western-transport has a weak seasonal signal (amplitude represents $8 \%$ of the monthly variance) and appears to be in better agreement with the vorticity of the Yucatan Current (Fig. 8) and with the LC extension (Figs. 9 and 10c). Therefore, a distinction needs to be made between Yucatan Current and Yucatan Channel dynamics.

The role of eddies in modulating the transport appears to be important though their origin and structure remain uncertain. Movies of MADT variability show the presence of cyclones or anticyclones propagating along the Cayman Sea modulating the flow either by full or partial crossings at Yucatan Channel. But there are other mesoscale features, such as the anticyclone within the LC bulge (Mildner et al. 2013) and/or the Cuban anticyclones (Kourafalou et al. 2017), that can either block the flow from the Caribbean depending on their position with respect to the Yucatan Channel, or enhance the flow toward the Caribbean on the eastern side of the channel. Extensions of the anticyclonic circulation within the Cayman Sea toward the Yucatan Channel (Rousset and Beal 2011) need to be considered too, though it remains to be determined whether this anticyclonic circulation is the result of wind forcing or an average produced by anticyclonic eddies passing through the Cayman Sea. Further downstream the focus has been to link LCFEs and LCE detachments with Caribbean eddies (Le Hénaff et al. 2012; Athié et al. 2012; Sheinbaum et al. 2016), but 
as shown by Kourafalou et al. (2017), the processes in the LC extension region also appear to modulate the formation of Cuban anticyclones and cyclones in the northwestern part of Cuba, which contribute to transport variability in the eastern Yucatan Channel. Clearly, the variability in the eastern channel is not just responding to Yucatan Current variations and has its own dynamics, most likely affecting the outflow at the Florida Straits and contributing to the west-east asymmetry in the Yucatan Channel flow.

In conclusion, due to the high variability in the Yucatan Channel-LC region on a wide range of frequencies, there are several processes that can impact the growing and retracting cycle of the LC and its associated transport and vorticity during a given year, not necessarily related to seasonal changes in the wind forcing, particularly the easterlies. The idea that wind forcing sets up the mean conditions in the LC system and that eddies and instabilities are just relatively small perturbations on top of that forced circulation cannot be clearly established from our work. In fact, this study suggests that eddies and other processes produce such a strong modulation that they need to be considered as important as the wind in setting the seasonal variability of the regional circulation. Different dynamic regimes appear to be dominant during different periods, and the reasons why is that the case remain to be determined.

Acknowledgments. Partial funding for this work comes from CICESE internal funds (Internal Project 36145). Partial funding comes from the National Council of Science and Technology of Mexico, Mexican Ministry of Energy, Hydrocarbon Trust, as part of the Gulf of Mexico Research Consortium (CIGoM); Project 201441. AVISO SSALTO/Duacs produced the altimeter products and distributed by Copernicus Atmosphere Monitoring Service Information, supported by the European Centre for Medium-Range Weather Forecasts (ECMWF) at http://marine.copernicus.eu. The wind data used in this work were the ERA-Interim database, distributed by ECMWF at https://www.ecmwf.int. The Florida Current cable section data are made freely available on the Atlantic Oceanographic and Meteorological Laboratory web page (www.aoml. noaa.gov/phod/floridacurrent/) and are funded by the DOC/NOAA/Climate Program Office/Ocean Observing and Monitoring Division. The captain Leobardo Ríos and the crew of the University of Mexico's (UNAM) B/O Justo Sierra are thanked for their participation in the CANEK program. Thanks are extended to Dr. Villy Kourafalou (Univ. of Miami/RSMAS) and an anonymous reviewer for their constructive criticism that greatly improved this work.

\section{REFERENCES}

Abascal, A. J., J. Sheinbaum, J. Candela, J. Ochoa, and A. Badan, 2003: Analysis of flow variability in the Yucatan Channel. J. Geophys. Res., 108, 3381, https://doi.org/ 10.1029/2003JC001922.

Alvera-Azcárate, A., A. Barth, and R. H. Weisberg, 2009: The surface circulation of the Caribbean Sea and the Gulf of Mexico as inferred from satellite altimetry. J. Phys. Oceanogr., 39, 640-657, https://doi.org/10.1175/2008JPO3765.1.

Amador, J. A., 1998: A climatic feature of the tropical Americas: The trade wind easterly jet. Top. Meteor. Oceanogr., 5 (2), 91-102.

Anderson, D. L., and R. A. Corry, 1985: Seasonal transport variations in the Florida Straits: A model study. J. Phys. Oceanogr., 15, 773-786, https://doi.org/10.1175/1520-0485(1985)015<0773: STVITF $>2.0 . C O ; 2$.

Athié, G., J. Candela, J. Ochoa, and J. Sheinbaum, 2012: Impact of Caribbean cyclones on the detachment of Loop Current anticyclones. J. Geophys. Res., 117, C03018, https://doi.org/ 10.1029/2011JC007090.

, J. Sheinbaum, R. Leben, J. Ochoa, M. R. Shannon, and J. Candela, 2015: Interannual variability in the Yucatan Channel flow. Geophys. Res. Lett, 42, 1496-1503, https:// doi.org/10.1002/2014GL062674.

Berrisford, P., and Coauthors, 2011: The ERA-Interim Archive: Version 2.0. ERA Rep. Series 1, 23 pp., https://www.ecmwf.int/ en/elibrary/8174-era-interim-archive-version-20.

Bunge, L., J. Ochoa, A. Badan, J. Candela, and J. Sheinbaum, 2002: Deep flows in the Yucatan Channel and their relation to changes in the Loop Current extensión. J. Geophys. Res., 107, 3233, https://doi.org/10.1029/2001JC001256.

Candela, J., S. Tanahara, M. Crepon, B. Barnier, and J. Sheinbaum, 2003: Yucatan Channel flow: Observations versus CLIPPER ATL6 and MERCATOR PAM models. J. Geophys. Res., 108, 3385, https://doi.org/10.1029/2003JC001961.

_ and Coauthors, 2019: The flow through the Gulf of Mexico. J. Phys. Oceanogr., 49, 1381-1401, https://doi.org/10.1175/ JPO-D-18-0189.1.

Chang, Y.-L., and L.-Y. Oey, 2012: Why does the Loop Current tend to shed more eddies in summer and winter? Geophys. Res. Lett., 39, L05605, https://doi.org/10.1029/2011GL050773.

$\longrightarrow$, and - , 2013: Loop Current growth and eddy shedding using models and observations: Numerical process experiments and satellite altimetry data. J. Phys. Oceanogr., 43, https://doi.org/10.1175/JPO-D-12-0139.1.

Emery, W. J., and R. E. Thomson, 2001: Data Analysis Methods in Physical Oceanography. 2nd ed. Elsevier, 654 pp.

Garcia-Jove, M., J. Sheinbaum, and J. Jouanno, 2016: Sensitivity of Loop Current metrics and eddy detachments to different model configurations: The impact of topography and Caribbean perturbations. Atmósfera, 29, 235-265, https://doi.org/10.20937/ ATM.2016.29.03.05.

Hall, C. A., and R. Leben, 2016: Observational evidence of seasonality in the timing of loop current eddy separation. Dyn. Atmos. Oceans, 76, 240-267, https://doi.org/10.1016/ j.dynatmoce.2016.06.002.

Hamilton, P., A. Lugo-Fernández, and J. Sheinbaum, 2016: A Loop Current experiment: Field and remote measurements. Dyn. Atmos. Oceans, 76, 156-173, https://doi.org/10.1016/ j.dynatmoce.2016.01.005.

Johns, W. E., and F. Schott, 1987: Meandering and transport variations of the Florida Current. J. Phys. Oceanogr., 17, 1128-1147, 
https://doi.org/10.1175/1520-0485(1987)017<1128:MATVOT> 2.0.CO;2.

Jouanno, J., and J. Sheinbaum, 2012: Seasonal and interannual modulation of the eddy kinetic energy in the Caribbean Sea. J. Phys. Oceanogr., 42, 2041-2055, https://doi.org/10.1175/ JPO-D-12-048.1.

_, — , B. Barnier, J.-M. Molines, L. Debreu, and F. Lemarié, 2008: The mesoscale variability in the Caribbean Sea. Part I: Simulations and characteristics with an embedded model. Ocean Modell., 23, 82-101, https://doi.org/10.1016/j.ocemod.2008.04.002. $\ldots, \ldots, \ldots$, and $\_$2009: The mesoscale variability in the Caribbean Sea. Part II: Energy sources. Ocean Modell., 26, 226-239, https://doi.org/10.1016/j.ocemod.2008.10.006.

_ - J. Ochoa, E. Pallàs-Sanz, J. Sheinbaum, F. Andrade-Canto, and J. Candela, 2016: Loop Current frontal eddies: Formation along the Campeche Bank and impact of coastally trapped waves. J. Phys. Oceanogr., 46, 3339-3363, https://doi.org/ 10.1175/JPO-D-16-0052.1.

Kourafalou, V. H., Y. Androulidakis, M. Le Hénaff, and H. Kang, 2017: The dynamics of Cuba Anticyclones (CubANs) and interaction with the Loop Current/Florida Current System. J. Geophys. Res. Oceans, 122, 7897-7923, https://doi.org/ 10.1002/2017JC012928

Leben, R. R., 2005: Satellite observations of Gulf of Mexico mesoscale circulation and variability. Circulation in the Gulf of Mexico: Observations and Models, Geophys. Monogr., Vol. 161, Amer. Geophys. Union, 181-201.

Le Hénaff, M., V. H. Kourafalou, Y. Morel, and A. Srinivasan, 2012: Simulating the dynamics and intensification of cyclonic Loop Current Frontal Eddies in the Gulf of Mexico. J. Geophys. Res., 117, C02034, https://doi.org/10.1029/ 2011JC007279.

Lin, Y., R. J. Greatbatch, and J. Sheng, 2009: A model study of the vertically integrated transport variability through the Yucatan Channel: Role of Loop Current evolution and flow compensation around Cuba. J. Geophys. Res., 114, C08003, https:// doi.org/10.1029/2008JC005199.

Liu, Y., and R. H. Weisberg, 2012: Seasonal variability on the West Florida Shelf. Prog. Oceanogr., 104, 80-98, https://doi.org/ 10.1016/j.pocean.2012.06.001.

Maul, G. A., 1977: The annual cycle of the Gulf Loop Current. Part I: Observations during a one-year time series. J. Mar. Res., 35, 29-47.

Meinen, C. S., M. O. Baringer, and R. F. Garcia, 2010: Florida Current transport variability: An analysis of annual and longer-period signals. Deep-Sea Res. I, 57, 835-846, https:// doi.org/10.1016/j.dsr.2010.04.001.

Mildner, T. C., C. Eden, and L. Czeschel, 2013: Revisiting the relationship between Loop Current rings and Florida Current transport variability. J. Geophys. Res. Oceans, 118, 6648-6657, https://doi.org/10.1002/2013JC009109.

Molinari, R. L., J. F. Festa and D. Behringer, 1978: The circulation in the Gulf of Mexico derived from estimated dynamic height fields. J. Phys. Oceanogr., 8, 987-996, https://doi.org/10.1175/ 1520-0485(1978)008<0987:TCITGO > 2.0.CO;2.

Nelson, C. S., 1977: Wind stress and wind stress curl over the California Current. NOAA Tech. Rep. NMFS SSRF-714, 87 pp., https://spo.nmfs.noaa.gov/sites/default/files/legacypdfs/SSRF714.pdf.

Ochoa, J., A. Badan, J. Sheinbaum, and J. Candela, 2003: CANEK Measuring transports in the Yucatan Channel. Nonlinear Processes in Geophysical Fluid Dynamics: A Tribute to the Scientific Work of Pedro Ripa, O. U. Velasco, J. Sheinbaum, and J. Ochoa, Kluwer Academic, 275-286.

Richardson, P. L., 2005: Caribbean Current and eddies as observed by surface drifters. Deep-Sea Res. II, 52, 429-463, https:// doi.org/10.1016/j.dsr2.2004.11.001.

Rousset, C., and L. M. Beal, 2010: Observations of the Florida and Yucatan Currents from the Caribbean Cruise Ship. J. Phys. Oceanogr., 40, 1575-1581, https://doi.org/10.1175/ 2010JPO4447.1.

—- and — 2011: On the seasonal variability of the currents in the Strait of Florida and Yucatan Channel. J. Geophys. Res., 116, C08004, https://doi.org/10.1029/2010JC006679.

Schmitz, W. J., Jr., 2005: Cyclones and westward propagation in the shedding of anticyclonic rings from the Loop Current. Circulation in the Gulf of Mexico: Observations and Models, Geophys. Monogr. Ser., Vol. 161, Amer. Geophys. Union, 241-261.

Schott, F. A., T. N. Lee, and R. Zantopp, 1988: Variability of structure and transport of the Florida Current in the period range of days to seasonal. J. Phys. Oceanogr., 18, 1209-1230, https://doi.org/ 10.1175/1520-0485(1988)018<1209:VOSATO > 2.0.CO;2.

Sheinbaum, J., J. Candela, A. Badan, and J. Ochoa, 2002: Flow structure and transport in the Yucatan Channel. Geophys. Res. Lett., 29, 1040, https://doi.org/10.1029/2001GL013990.

- G. Athié, J. Candela, J. Ochoa, and A. Romero-Arteaga, 2016: Structure and variability of the Yucatan and loop currents along the slope and shelf break of the Yucatan channel and Campeche bank. Dyn. Atmos. Oceans, 76, 217-239, https://doi.org/10.1016/j.dynatmoce.2016.08.001.

Smith, S. D., 1980: Wind stress and heat flux over the ocean in gale force winds. J. Phys. Oceanogr., 10, 709-726, https://doi.org/ 10.1175/1520-0485(1980)010<0709:WSAHFO > 2.0.CO;2.

Sturges, W., 1994: The frequency of ring separations from the Loop Current. J. Phys. Oceanogr., 24, 1647-1651, https://doi.org/ 10.1175/1520-0485(1994)024<1647:TFORSF $>2.0$.CO;2.

— Mexico. J. Mar. Res., 41, 639-653, https://doi.org/10.1357/ 002224083788520487.

Wang, C., 2007: Variability of the Caribbean Low-Level Jet and its relations to climate. Climate Dyn., 29, 411-422, https://doi.org/ 10.1007/s00382-007-0243-z.

Weisberg, R. H., and Y. Liu, 2017: On the Loop Current penetration into the Gulf of Mexico. J. Geophys. Res. Oceans, 122 9679-9694, https://doi.org/10.1002/2017JC013330. 